\title{
MATERIALIDAD Y ESTRUCTURA DE UN TEMPRANO CANCIONERO COLECTIVO INCUNABLE $\left(86^{*} R L\right) *$
}

\author{
Maria Mercè López Casas \\ Universidade de Santiago de Compostela \\ mamerce.lopez@usc.es
}

En varias ocasiones Dorothy Severin nos ha recordado a los investigadores que estamos -o estábamos- más pendientes del estudio de la poesía amatoria de cancionero que de la poesía moral y religiosa, que en verdad fue la más leída y difundida, especialmente en el reinado de los Reyes Católicos. De hecho Severin llevó a cabo la edición de varios de los cancioneros didácticos «olvidados» a los que aludía, como LB3 ${ }^{1}, \mathrm{HH} 1$ y SV2². A partir del análisis del contenido de los cancioneros de Egerton (LB3) y Oñate-Castañeda (HH1) la autora afirma lo siguiente:

en los cancioneros compuestos entre 1482 y 1496 (fecha de la impresión del Cancionero de Juan del Encina) predominaron las composiciones de contenido político, didáctico, moral y religioso. Debido fundamentalmente a las circunstancias que rodearon el afianzamiento de los Reyes Católicos en el trono, alrededor de los cuales se desarrolló una intensa campaña literaria; interesaba

${ }^{*}$ Este trabajo se enmarca dentro del proyecto Cancionero, romancero y fuentes impresas, del Ministerio de Economía, Industria y Competitividad (FFI2017-86313-P), financiado por la Agencia Estatal de Investigación (AEI) y el Fondo Europeo de Desarrollo Regional (FEDER/UE), cuyo investigador principal es Josep Lluís Martos.

${ }^{1}$ Cito los cancioneros con las siglas ya canónicas de Dutton, así como los números de identidad de los poemas (Brian Dutton, Catálogo-índice de la poesía cancioneril del siglo $\mathrm{XV}$, Madison, The Hispanic Seminary of Medieval Studies, 1982; y El Cancionero del Siglo XV c. 1360-1520, Salamanca, Universidad, 1990-1991, 7 vols.).

${ }^{2}$ El Cancionero de Oñate-Castañeda, ed. de Dorothy S. Severin; introd. de Michel Garcia, Madison, The Hispanic Seminary of Medieval Studies, 1990. Dorothy S. Severin, Two Spanish songbooks: The cancionero capitular de la Colombina (SV2) and The cancionero de Egerton (LB3), Liverpool, Liverpool University Press, 2000. 
consolidar el proceso político y la reforma, de manera que se dejó a un lado las frivolidades cortesanas de otros tiempos ${ }^{3}$.

En este período fijado por Severin se estampó en Zaragoza, en las prensas de Pablo Hurus, el Cancionero de Ramón de Llavia, buen ejemplo de la poesía cancioneril de tendencia moral y religiosa.

A pesar de que $86^{*} \mathrm{RL}$ forma parte de la nómina de los primeros cancioneros colectivos impresos, ha sido poco estudiado en su conjunto. Sí se ha tenido en cuenta para poemas concretos compilados en él, de Juan de Mena, de Jorge Manrique o de fray Íñigo de Mendoza por citar algunos, pero no fue hasta 1945 cuando se realizó un estudio pormenorizado y una edición completa del mismo, llevados a cabo por Rafael Benítez Claros ${ }^{4}$. No podemos dejar de lado, a la hora de explicar la poca atención que ha recibido el Cancionero, que Fernán Pérez de Guzmán es el autor más representado, y que además abre la colectánea ${ }^{5}$ Y si el poeta en su época gozó de gran estima entre sus coetáneos, especialmente por su vena religiosa y didáctico-moral ${ }^{6}$, como ponen de manifiesto los trece manuscritos cuatrocentistas que empiezan con sus obras (GB1, HH1, KK17, MM1, MM2, MM3, MN6, MN10b, MN29, NH4, PN5,

${ }^{3}$ Dorothy S. Severin «El cancionero didáctico de la Colombina», en Actas del X congreso de la Asociación Internacional de Hispanistas, ed. de A. Vilanova, Barcelona, PPU, 1992, I, p. 331. Y la misma idea expresada en «Songbooks as Isabelline Propaganda: The case of Oñate and Egerton», Medieval Spain. Culture, Conflict, and Coexistence: Studies in Honour of Angus Mackay, ed. de R. Collins, A. Goodman, London, Palgrave Macmillan, 2002, p. 180.

${ }^{4}$ Cancionero de Ramón de Llavia, Madrid, Sociedad de Bibliófilos Españoles, 1945.

${ }^{5}$ Con siete poemas ocupa 52 folios del cancionero (53 \%). Con dos poemas están Juan de Mena, Gómez Manrique, Íñigo de Mendoza, Jorge Manrique, Juan Álvarez Gato, y Gonzalo Martínez de Medina. Y con un solo poema, Ervías, Fernán Ruiz de Sevilla, Fernán Sánchez Calavera y fray Gauberte.

${ }^{6} \mathrm{Al}$ estudiar el conjunto de la poesía de Pérez de Guzmán se observan dos líneas diferenciadas en su transmisión textual. La poesía más temprana -los poemas amorosos, cortesanos y de circunstanciasfigura en unos testimonios distintos a los que contienen su corpus moral, didáctico y religioso, que, en general, está recopilado en otros diferentes. Trato de este asunto en «La poesía de Fernán Pérez de Guzmán en el Cancionero General de 1511», en Avatares y perspectivas del medievalismo ibérico, coord. de I. Tomassetti, ed. de R. Alviti, A. Garribba, M. Marini y D. Vaccari, San Millán de la Cogolla, Cilengua, 2019, II, pp. 1136-1140.

${ }^{7}$ Kobenhavn, Det Kongelige Bibliothek, GKS 435 folio. Siguiendo el sistema de Dutton se le podría asignar la sigla KK1. Supe de la existencia de este códice por M. ${ }^{a}$ Jesús Díez Garretas, Un cancionero para Álvar García de Santamaría. «Diversas virtudes y vicios» de Fernán Pérez de Guzmán, Tordesi1las, Universidad de Valladolid-Instituto de Estudios de Iberoamérica y Portugal, 2000, pp.73-74. Ahora también en BETA (Bibliografía Española de Textos Antiguos). Dir. Charles B. Faulhaber, The Bancroft Library. University of California, Berkeley, 1997, Bibliografía manid 6113. [En línea]. Enlace: <http:// vm136.lib.berkeley.edu/BANC/philobiblon/beta_en.html> [Consulta: 20/10/2019]. Juan Pablo Ortiz Hernández ha realizado su tesis sobre dicho cancionero: Poética doctrinal: la edición del cancionero de Otte Brahe, University of Calgary, 2007 (disponible en el servidor de la Universidad: https://prism. ucalgary.ca/bitstream/handle/1880/46459/Ortiz_Hernandez.pdf?sequence=1\&isAllowed=y). Debo la referencia a BETA, bibid 8008 . 
PN6 y SA9b) ${ }^{8}$, en los siglos XIX y xx su obra poética no ha despertado gran interés $^{9}$ entre la crítica ${ }^{10}$. Pero volvamos a las últimas décadas del siglo Xv: cuando Ramón de Llavia escogió las poesías del señor de Batres para abrir su cancionero, entonces sí era un autor prestigioso, que aún no había aparecido en ningún cancionero impreso, motivo nada desdeñable para un editor atento y listo, también en los primeros tiempos de la imprenta hispánica ${ }^{11}$.

\footnotetext{
${ }^{8}$ Y está en varios manuscritos más: LB3, MH1, MN23, MN29, MN33*, MP2, PN9, PN13 y SV2.

${ }^{9}$ Ya a mediados del siglo xviI, Juan Antonio de Vera Zúñiga (Conde de Roca), en el Centón Epistolario del bachiller Fernan Gómez de Cibdarreal. Generaciones y Semblanzas del Noble Caballero Fernán Pérez de Guzmán. Claros Varones de Castilla, y Letras de Fernando de Pulgar, señalaba el interés que despertaba Pérez de Guzmán por su prosa, en contraste con el renombre que tenía en su época por sus poemas: «Sin embargo de ser estas obras en prosa las que han dado nombre y reputación á Fernan Perez, en su tiempo era mas celebrado por sus poesías», Madrid, Imprenta Real de la Gazeta, 1775, f. 190v.

${ }^{10} \mathrm{Me}$ refiero sobre todo a la edición de sus poemas teniendo en cuenta todos los testimonios conservados. Por suerte contamos con los trabajos de M. ${ }^{a}$ Jesús Díez Garretas. Destacaré aquí sus aportaciones más importantes, donde además se pueden encontrar todas las obras de referencia y estudios sobre la poesía de Pérez de Guzmán. En colaboración con M. ${ }^{a}$ Wenceslada de Diego Lobejón ha editado el largo poema de Diversas virtudes y vicios, ob. cit. En fecha reciente ha llevado a cabo la edición de dos textos poéticos más: «La Confesión rimada de Fernán Pérez de Guzmán: estudio y edición», en Revista de Cancioneros Impresos y Manuscritos, 3 (2014), pp. 1-131. [En línea]. Enlace: $<$ https://rcim.ua.es $>$ [Consulta: 10/10/2019]. Ver también de Díez Garretas «La transformación textual en la Confesión rimada de Fernán Pérez de Guzmán: las variantes de los impresos», en La poesía en la imprenta antigua, ed. de J. L. Martos, Alacant, Publicacions de la Universitat d'Alacant, 2014, pp. 61-78). Y «La Doctrina que dieron a Sara de Fernán Pérez de Guzmán: estudio y edición crítica», en Revista de Cancioneros Impresos y Manuscritos, 7 (2018), pp. 66-149 (ver al respecto además «Los testimonios de La doctrina que dieron a Sara de Fernán Pérez de Guzmán», en eHumanista, 32 (2016), pp. 258-268, y «La Doctrina que dieron a Sara de Fernán Pérez de Guzmán: entre la variante y la doble versión», en Variación y testimonio único. La reescritura de la poesía, ed. de J. L. Martos, Alacant, Universitat d'Alacant, 2017, pp. 85-97). Cabe reseñar también dos tesis doctorales sobre la poesía de Pérez de Guzmán: José Antonio Barrio Sánchez, El Cancionero de Fernán Pérez de Guzmán, Madrid, UNED, 1992 (director: Miguel Ángel Pérez Priego); y Maria Mercè López Casas, «Loores de los claros varones de España» de Fernán Pérez de Guzmán: Estudio de la transmisión textual, Barcelona, Universitat de Barcelona, 1994 (director: Vicenç Beltran).

En cambio sus obras en prosa, especialmente las Generaciones y semblanzas, han gozado de varios estudios y ediciones (ver la bibliografía de referencia, amén de su estudio en Vicenç Beltran «Generaciones y semblanzas», en el Diccionario filológico de literatura medieval española: textos y transmisión, ed. de C. Alvar y J. M. Lucía Megías, Madrid, Castalia, 2002, pp. 511-514). También fue editado el Mar de historias por Raymond Foulché Delbosc: «Fernán Pérez de Guzmán, Mar de istorias», en Revue Hispanique, 16 (1913), pp. 442-622, y por Joaquín Rodríguez Arzúa (Madrid, Atlas, 1944). Recientemente ha sido editado por Andrea Zinato: Fernán Pérez de Guzmán, Mar de historias, Padova, Unipress, 1999. Además sobre el Mar de Historias ver de A. Zinato, «La conoscenza dell'altro tra Medioevo e Umanesimo», Rassegna Iberistica, 88 (2008), pp. 3-23; y «Poesías y “estorias”: Fernán Pérez de Guzmán», en Literatura y ficción: «estorias», aventuras y poesía en la Edad Media, ed. de Marta Haro Cortés, València, Publicacions de la Universitat de València, 2015, vol. 2, pp. 775-791. Zinato está preparando la edición de la traducción de Séneca realizada a instancias de Pérez de Guzmán: «Para la edición crítica de la traducción castellana medieval de las Epistulae morales de Séneca encargada por Fernán Pérez de Guzmán», en Estudios de literatura medieval en la Península Ibérica, ed. de C. Alvar, San Millán de la Cogolla, 2015, pp. 1195-1216.

${ }^{11}$ Aproximadamente por las mismas fechas que $86 * \mathrm{RL}$-si aceptamos la datación de Dutton- se imprime un poema de Fernán Pérez de Guzmán en un incunable fechado gracias a su colofón (87PG). La poesía en cuestión, que no está en $86 *$ RL, son las «Coplas que escribió a la muerte de Alfonso de Carta-
} 
En estas páginas presentaré las características externas de $86 * \mathrm{RL}$, teniendo en cuenta los tres ejemplares que he inspeccionado personalmente ${ }^{12}$, y que me han permitido aproximarme a lo que Jaime Moll define como «ejemplar ideal», es decir, «el que ofrece el estado más perfecto de la obra según la intención del autor, editor o impresor» ${ }^{13}$. Para después, ofrecer su estructura o descripción interna de los textos que lo conforman, pues un cancionero es siempre un testimonio textual, que acoge en sus páginas poemas de determinados poetas que fueron seleccionados por el autor de la colección.

\section{Análisis material}

[Cancionero de Ramón de Llavia] ${ }^{14}$ [Pérez de Guzmán, Fernán, Juan de Mena et al]. Sin indicaciones tipográficas, pero fue estampado en Zaragoza,

gena» (ID 1937 Aquel seneca espiro). El poema figura como el complemento final de un texto en prosa, el Oracional de Alfonso de Cartagena, escrito como respuesta a unas cuestiones que le había planteado Pérez de Guzmán. El libro se estampó en Murcia con el título Oracional de Fernán Pérez, por Gabriel Luis de Arinyo y Lope de la Roca, el 26 de marzo de 1487. Según Julián Martín Abad (Los primeros tiempos de la imprenta en España (c. 1471-1520), Madrid, Laberinto, 2003, p. 80), Gabriel Luis de Arinyo fue más bien el costeador, mientras que Lope de la Roca, cuyo nombre alemán era Wolf von Stein, fue propiamente el impresor. Amparo García Cuadrado, «La llegada de la imprenta a Murcia: algunos de sus protagonistas», en Murgetana, 113 (2005), pp. 33-45, sugiere, a partir de un documento publicado por Torres Fontes, que Diego Rodríguez de Almela fue el editor de 87PG, y de otros dos impresos murcianos. La investigadora concluye que el notario valenciano Arinyo actuó como impresor, por lo menos en el incunable del Oracional. La inclusión de las «Coplas» de Pérez de Guzmán en el libro del Oracional podría haber sido decisión del editor o de la sociedad formada por Arinyo y Lope de la Roca, pues en la tradición manuscrita del Oracional no lo he encontrado. El poema no volverá a ser impreso hasta el Cancionero General de 1511. Desde el punto de vista textual, Hernando del Castillo siguió la versión de 87PG (ver López Casas, «La poesía de Fernán Pérez de Guzmán en el Cancionero General de 1511», en Avatares... ob. cit., pp. 1151-1152).

${ }^{12}$ Dos en la BNE (I-2567 e I-2892), y uno en la Biblioteca del Monasterio de San Lorenzo de El Escorial $\left(32-1-131^{\circ}\right)$. De los tres, el mejor conservado, con todos los folios, y el que mantiene la estructura original y el texto sin corromper es el ejemplar escurialense, por lo que la descripción se basará principalmente en él, contrastando sus características con los demás ejemplares.

${ }^{13}$ Definición de Jaime Moll, «Problemas bibliográficos del libro del Siglo de Oro», en Boletín de la Real Academia Española, 59 (1979), p. 76. Ahora también, con el mismo título, pero revisado y ampliado en el libro Problemas bibliográficos del libro del Siglo de Oro, Madrid, Arco Libros, 2011, pp. 46-47. Martín Abad, ob. cit., p. 185, indica que fue Fredson Bowers en 1949 quien primero acuñó la expresión «ideal copy», la cual debía poseer todo aquello que en la intención del editor constituía la forma definitivamente revisada del libro.

${ }^{14}$ Caballero CCCI, p. 13 (Raimundo Diosdado Caballero, De prima typographiae Hispanicae aetate specimen, Roma, Antonius Fulgonius, 1793). Méndez 9 (Francisco Méndez, Typographia española ó Historia de la introducción, propagación y progresos del arte de la imprenta en España, Madrid, Imp. de la Vda. de Joachim Ibarra, 1796). Brunet II: 1837 (Jacques Charles Brunet, Manuel du libraire et de l'amateur de livres, Paris, Librairie de Firmin Didot Frères, Fils etc, 1861, 10 vols.). Graesse II: p. 32 (Jean George Théodore Graesse, Trésor de livres rares et précieux ou nouveau dictionnaire bibliographique, Dresde, Rudolf Kuntze, Libraire-Editeur, 6 vols, 1859-1861; reimpresión Milano, Görlich, 1950). Gallardo III: 2859 (Bartolomé José Gallardo, Ensayo de una biblioteca española de libros raros y y curio- 


\section{en el taller de los Hurus, en concreto por Pablo Hurus ${ }^{15}$. La fecha estaría}

sos, Madrid, Imprenta y Estenotipia de M. Rivadeneyra, 1863-1889, 4 vols.). Salvá I: 185 (Pedro Salvá y Mallén, Catálogo de la Biblioteca de Salvá, Valencia, Imprenta de Ferrer de Orga, 1872, 2 vols.). Heredia II: 1641 (Catalogue de la Bibliothèque de M. Ricardo Heredia, Comte de Benahavís, Paris, Em. Paul, L. Huard et Guillemin, 1891-1894, 4 vols.). Copinger II: 3628 (Walter A. Copinger, Supplement to Hain's Repertorium Bibliographicum, London, 1895-1902). Proctor 9516 (Robert Proctor, An index to the early printed books in the British Museum from the invention of printing to the year MD, with notes of those in the Bodleian Library, 1898-1903). Haebler 387 (Conrado Haebler, Bibliografia ibérica del siglo XV, La Haya, Martinus Nijhoff-Leipzig, Karl V. Hiersemann, 1903, p. 183-184; y Bibliografía ibérica del siglo Xv. Segunda Parte, La Haya, Martinus Nijhoff-Leipzig, Karl V. Hiersemann, 1917 [ed. facsímil, Madrid, Julio Ollero, 1992], p. 111 y p. 255). Sánchez 25 (Juan Manuel Sánchez, Bibliografia zaragozana del siglo $X V$, Madrid, Imprenta Alemana, 1908). Lambert VII, p. 50 (A. Lambert, «Les origines de l'imprimerie à Saragossa», en Revista de Archivos, Bibliotecas y Museos, 33 (1915), pp. 29-50). BMC X: p. 27, IB52163 (Catalogue of books printed in the xvth century now in the British Museum. Part X: Spain-Portugal, London, The Trustees of the British Museum, 1971, 10 vols.). Vindel IV: 31 (Francisco Vindel, El Arte tipográfico en España en el siglo xv: Zaragoza, Madrid, Ministerio de Asuntos Exteriores-Dirección General de Relaciones Culturales, 1949, y Vindel 143 (Catálogo-Índice de los Incunables impresos en España existentes en la Biblioteca Nacional. Con algunas observaciones sobre las Bibliotecas Públicas y sobre la adquisición de libros para las mismas, Madrid, Francisco Vindel, 1935). CIBN 482 (Diosdado García Rojo y Gonzalo Ortiz de Montalbán, Catálogo de Incunables de la Biblioteca Nacional, Madrid, BN, 1945). Palau VIII: 144873 (Antonio Palau y Dulcet, Manual del librero hispanoamericano, vol. 8, Barcelona, A. Palau, 1954-1955). Simón Díaz 2857 (José Simón Díaz, Bibliografia de la literatura hispánica. III.1, Madrid, CSIC, Instituto Miguel de Cervantes, 1963). IBE 1407 (Francisco García Craviotto, Catálogo General de de Incunables en Bibliotecas Españolas, Madrid, 1989-1990). Viña 675 (José M. Viña Liste y Juan Casas Rigall, Cronología de la literatura española. I. Edad Media, Madrid, Cátedra, 1991). Pallarés 30 (Miguel Ángel Pallarés Jiménez, «Actualización del catálogo de incunables de Zaragoza», en La imprenta de los incunables de Zaragoza y el comercio internacional del libro a finales del siglo XV, Zaragoza, Institución Fernando el Católico, 2003, pp. 843-879). Martín Abad I: C-24 (Julián Martín Abad, Catálogo bibliográfico de la colección de incunables de la Biblioteca Nacional de España, Madrid, BNE, 2010). ISTC i100256500 (The Incunabula Short Title Catalogue [International database of 15th-century European printing, created by the British Library with contributions from institutions worldwide], desde 1980-. [En línea] Enlace: <http://www.bl.uk/catalogues/istc/index.html> [Consulta: 14/10/2019]. Dutton 86*RL (Cancionero...; en el Catálogo-Índice... 94*RL). CCPB 000108642 (Catálogo Colectivo del Patrimonio Bibliográfico Español, 2011-. [En línea]. Enlace: <http://catalogos.mecd.es/CCPB/ccpbopac/> [Consulta: 6/2/2019]). GW M18558 (Gesamtkatalog der Wiegendrucke, Hrsg. von der Kommision für Gesamtkatalog der Wiegendrucke. 2. Aufl. Stuttgart, etc., Anton Hiersemann, 1968-. [En línea] Enlace: $<$ https://www.gesamtkatalogderwiegendrucke.de> [Consulta: 20/1/2020]). BETA Texid 1569 (Bibliografia Española de Textos Antiguos, PhiloBiblon. Dir. Charles B. Faulhaber. The Bancroft Library. University of California, Berkeley, 1997-. [En línea]. Enlace: $<$ http://vm136.lib.berkeley.edu/BANC/philobiblon/ beta_en.html> [Consulta:13/5/2019]).

${ }^{15}$ Se ha considerado desde Haebler que el artífice del impreso fue Juan Hurus, y gran parte de los bibliógrafos siguieron su parecer, así Sánchez, Vindel, García Craviotto, y todavía en fecha reciente, Pallarés, y así sigue figurando en el Gesamtkatalog y en el Catálogo Colectivo del Patrimonio Bibliográfico Español. Sin embargo, Lambert, BMC, ISTC, Brian Dutton y Julián Martín Abad consideran que fue Pablo Hurus el impresor. De hecho, cuando Haebler en 1917 se refiere a los tipos que se usaron en el taller de los Hurus, no hace distinción, pues en la sección y listado de tipos de la imprenta zaragozana, Pablo y Juan Hurus figuran juntos (ver Bibliografia... Segunda parte, pp. 254-255). Gracias al avance que ha supuesto la base de datos del Typenrepertorium der Wiegendrucke, Berlín, Staatsbibliothek zu Berlin. [En línea]. Enlace: $<$ https://tw.staatsbibliothek-berlin.de/>, se ha podido concretar más y afirmar que efectivamente los dos Hurus en algunos impresos emplearon los mismos tipos (lo que no significa que necesariamente trabajaran juntos). Y es lo que sucedió con los tipos 1: $99 \mathrm{G}$ y $2^{*}: 134 \mathrm{G}$ que se usaron 
situada entre 1488 y 1490, o bien alrededor de 1486 (de ahí la sigla que le atribuyó Dutton $86^{*}$ RL), adelantando en dos años la fecha más comúnmente aceptada. En cualquier caso, la horquilla iría desde 1486 hasta 1490 (datación aproximada $)^{16}$.

Formato in folio. 98 folios de papel, sin foliación. Tipografía gótica, con tipos de dos fundiciones. El texto de los poemas, así como la mayoría de rúbricas iniciales e internas (titulillos), con un tipo $99 \mathrm{G}$, con el diseño de la $\mathrm{M}_{95}$ de Haebler ${ }^{17}$. Y para las rúbricas de encabezamiento de la tabla ${ }^{18}$, de algunos poemas - de Pérez de Guzmán, Juan de Mena y Gómez Manrique ${ }^{19}$ - y para

para el Cancionero de Ramón de Llavia, fueron empleados por Pablo Hurus (Zaragoza Offizin 5) pero también por Juan Hurus (Zaragoza Offizin 4). Ver $<$ https://tw.staatsbibliothek-berlin.de/of0231>. A pesar de dicha coincidencia con los tipos, hay rasgos distintivos que no se han escapado a la atenta mirada y experiencia de Julián Martín Abad y de Brian Dutton, así como del BMC e ISTC, lo que les ha llevado a afirmar taxativamente que el impresor fue Pablo Hurus.

${ }^{16} \mathrm{Si}$ tenemos en cuenta la documentación exhumada por Pallarés y el catálogo que él publica $(o b$. cit. pp. 846-551), Pablo Hurus, desde 1481 a 1485, fue el responsable en solitario (y a veces como editor) de 20 impresos zaragozanos (números del 5 al 23, y quizás también el 24). El 28 de julio de 1486 nombró procurador para negocios a su hermano Juan Hurus, que se hizo cargo de la jefatura de la oficina tipográfica, en lo técnico y en lo comercial (ibidem, pp. 96-97), hasta el año 1490 en que Juan Hurus desaparece, quizá muriera (ibidem, p. 108). En enero de 1491 empieza la segunda etapa de Pablo Hurus en el negocio, que durará hasta 1499, año en que vendió la imprenta a la sociedad formada por Coci, Appentegger y Hutz (ibidem, pp. 141-147). Mientras regentó el negocio Juan Hurus, su hermano Pablo, que era a su vez mercader, desaparece de la documentación zaragozana (¿hizo otro viaje a Alemania como ya había hecho en 1480 dedicado a otros negocios, entre otras cosas, la adquisición de material para el taller?). De hecho Frederick J. Norton, en La imprenta en España 1501-1520 (con un nuevo Índice de libros impresos en España, 1501-1520 por Julián Martín Abad, Madrid, Ollero \& Ramos, 1997, p. 119) dice al respecto que su hermano Juan le sustituyó durante una larga ausencia en los años 1488-1490. Lo cierto es que no tenemos datos sobre qué sucedió en aquellos años con Pablo Hurus, quizá simplemente no se hayan conservado, pero si en julio de 1486 dejó a su hermano Juan a cargo del taller, sería posible que así fuera. De manera que la fecha propuesta por Dutton, que retrotrae la impresión del Cancionero de Ramón de Llavia hacia 1486 estaría más acorde con la ausencia de Pablo Hurus en 1488-1490.

${ }^{17} \mathrm{Se}$ trata de una fuente que perteneció a la imprenta zaragozana de Hurus, con uso documentado desde 1485 hasta 1491, según el BMC; y hasta 1495 según el GW. Registro completo de dicha tipografía en el TW ID ma01243 [En línea]. Enlace: <https://tw.staatsbibliothek-berlin.de/ma01243> [Consulta: 20/12/2019].

${ }^{18}$ En el primer folio del cancionero se destaca especialmente la tabla, pues lleva encabezamiento y rúbrica de conclusión. En cambio el prólogo no lleva rúbrica alguna, a pesar de que es el texto que abre el volumen. Ambas rúbricas están centradas con respecto a la caja de escritura. El resto de encabezamientos con este tipo $134 \mathrm{G}$ también van centradas dentro de la caja de la columna de texto. Rúbrica inicial de la tabla, f. [1r]: Tabla del presente libro. Rúbrica final de la tabla, f. [1v]: Son las obras en el presente | volumen contenidas .xviiij.

${ }^{19}$ En algunas de estas rúbricas solo está la primera línea con el tipo $134 \mathrm{G}$, especialmente si es larga: f. [2r] Coblas fechas por fernan perez de guzman de | (el resto a continuación, va con el tipo 99G) vicios \& virtudes: \& ciertos ymnos de nuestra senyora

f. [33r] Los siete pecados $\mid$ mortales que fizo $\mid$ Johan de mena

f. [39v] Aqui fallecio Johan | (el resto a continuación, con 99 G) de mena \& por fallecimiento su $\mid$ yo prosigue gomez manrique \& $\mid$ faze un breve prohemio en esta $\mid$ obra començada por johan de $\mid$ mena y acabase por el

f. [49v] Confession rimada por fer | (el resto con tipo 99G) nan perez de guzman 
las de conclusión ${ }^{20}$, se emplea un tipo $134 \mathrm{G}^{21}$. Sin portada ni título. Sin iniciales grabadas ni de ningún tipo. El cancionero empieza directamente en el primer folio (recto) del primer cuaderno ${ }^{22}$ con un prólogo en prosa (sin rúbrica), $y$ en el tercio inferior comienza la tabla, que se completa en el verso de este folio inicial. De 42 a 44 líneas ${ }^{23}$. A excepción del folio primero (caja de escritura: $225 \times 150 \mathrm{~mm}$ ) la disposición del texto -los poemas-es a dos columnas, con caja distinta según los textos, pues no es lo mismo que la estrofa sea de versos octosílabos que dodecasílabos ${ }^{24}$, por tanto va oscilando en función de los poemas de que se trate ${ }^{25}$. Del mismo modo va cambiando el espacio que

f. [53v] De los siete pecados mortales (se trata de una rúbrica interna dentro de la Confesión rimada; es una excepción porque las internas en el resto del volumen nunca van con este tipo de letra más grande) f. [61r] Contra los que dizen que di $\mid$ (el resto con tipo 99G) os en este mundo nin da bien por bien $\mid$ nin mal por mal (es un poema de Fernán Pérez de Guzmán).

f. [65r] Coplas fechas por fernan pe | (el resto con tipo 99G) rez de guzman diregidas a las nobles | mujeres para su doctrina.

${ }^{20}$ Ya hemos visto la rúbrica del final de la tabla, pero hay otra de conclusión de un poema: en la continuación de Gómez Manrique de Los siete pecados mortales de Juan de Mena. Ocupa en la columna, no por la medida de la letra, sino por el espacio libre que se ha dejado, el equivalente a una estrofa de 8 versos: [49r] Fin.

${ }^{21}$ No puedo concretar el diseño de la $\mathrm{M}$, porque no tengo ninguna para comparar, pero sí he hecho la comparación con las otras mayúsculas de las rúbricas de encabezamiento, especialmente con la $\mathrm{A}, \mathrm{y}$ coinciden con las del tipo $2^{*}:$ 134G. Registro completo de dicha tipografía en el TW ID ma01246. [En línea] Enlace: <https://tw.staatsbibliothek-berlin.de/ma01246> [Consulta: 20/12/2019].

${ }^{22}$ Ya Salvá especifica: «Principia en la hoja sign. aj, sin frontis por no haberlo tenido nunca», ob. cit., I, p. 95. Podría pensarse que había un primer folio con el título y que este se hubiera perdido, pero ningún ejemplar lo ha conservado. De hecho solo Méndez (ob. cit., p. 383) dice «Tomo falto» referido a que interpreta que había un folio perdido que constituía la portada, porque luego la descripción es idéntica a la de los demás repertorios; es decir, empieza con el prólogo en el primer folio del primer cuaderno (ver Julián Abad, «El día después del Catálogo bibliográfico de la Colección de Incunables de la Biblioteca Nacional de España», en «Vir bonus dicendi peritus»: Studies in honor of Charles B. Faulhaber, ed. de A. Cortijo Ocaña, A. M. Gómez-Bravo, M. Morrás, New York, Hispanic Seminary of Medieval Studies, 2014, pp. 129-153 [132]).

${ }^{23}$ Todos los bibliógrafos ponen de 40 a 42 líneas, pero lo habitual es de 42 y más. Encontramos de 43 (sirvan de ejemplo, ff. [5v], [34v], [70r], [72r], [76r], [80v], [90v]), de 44 (ff. [14v], [60r], [71v], [73r], [76r], [90r]..), y también de 45 líneas (ff. [2v], [4v], [18r], [69v], [71r], [72r], [90r]...).

${ }^{24} \mathrm{Si}$ el folio tiene columnas de versos octosílabos la caja de ancho puede oscilar entre 125 y $130 \mathrm{~mm}$ ([ff. [6v] y [96v]). Si hay una columna de cada tipo de verso, oscila entre 135 y $140 \mathrm{~mm}$ (ff. [8v]-[9r]). Y si ambas columnas son de dodecasílabos la caja puede llegar hasta $160 \mathrm{~mm}$ ([ff. $57 \mathrm{v}$ y $67 \mathrm{v}]$ ). Aún se observa más variabilidad en el largo; hay caja de hasta $270 \mathrm{~mm}$ (f. [38v]).

${ }^{25}$ Incluso en un mismo poema. Esto sucede con el tratado de Diversas virtudes y vicios, poema peculiar, que carece de estructura, como ha señalado Dorothy S. Severin, pues no es un debate sistemático sino que Pérez de Guzmán dedica «dos o tres hasta seis o nueve estrofas a un gran número de tópicos alrededor de las virtudes y vicios, los pecados mortales y muchos otros temas, sin tener en cuenta la organización del poema», D. Severin, «Política y poesía en la corte de Isabel la Católica», en Dejar hablar a los textos: Homenaje a Francisco Marquez Villanueva, ed. de P. M. Piñero Ramírez, Sevilla, Universidad de Sevilla, 2005, p. 240. En $86^{*}$ RL, en el folio [8v] hay una columna (a) con 4 estrofas en octosílabos y en la columna siguiente (b), otro grupo de 4 estrofas, que tratan un tema distinto (De ocio vicioso $\&$ virtuofo), cuyos versos son dodecásilabos. Dicha alternancia también se presenta en la Confesión rimada de Pérez de Guzmán (ff. 49r-65r), lo que altera lógicamente la caja. Y cuando nos referimos a otros autores, según 
queda entre las columnas de texto ${ }^{26}$. En cuanto a la impaginación, suele haber 4 estrofas por columna cuando se trata de octavas o de estrofas de menos versos, y hay 3 por columna cuando son estrofas de 9,10 o 12 y $13^{27}$, incluidas las rúbricas de encabezamiento y las rúbricas internas ${ }^{28}$.

El volumen está formado por 13 cuadernos: 10 cuaterniones y 3 terniones con signatura tipográfica ${ }^{29}$ en letra minúscula con marcación hasta la mitad más una, es decir, no sólo está la secuencia alfanumérica en las primeras hojas, es decir, hasta la 4 en los cuaterniones y hasta la 3 en los terniones, sino que también encontramos signatura en la siguiente hoja, la primera de la segunda mitad del cuaderno ${ }^{30}$ :

$$
a-c^{v+3} d^{i i i j+2} e-k^{v+3} 1-m^{i i j+2} n^{v+3}
$$

Hay una errata en la signatura eij [f. 32], pues en lugar de la letra «e» hay una $\langle\mathrm{c}\rangle: c i j^{31}$. Sin reclamos, ni registro de cuadernos.

No presenta calderones, que sí figuran en otras ediciones de textos poéticos que estampó Pablo Hurus ${ }^{32}$. En cuanto a la ortografía ${ }^{33}$ se observa la

los poemas encontramos la alternancia igualmente: textos en dodecásilabo o en octosílabo, por tanto la caja va variando a lo largo del impreso.

${ }^{26}$ Cuando en el folio se trata de poemas en verso dodecasílabo normalmente es de $10 \mathrm{~mm}$ o $12 \mathrm{~mm}$, y si el verso es octosílabo, de $30 \mathrm{~mm}$. Cuando hay una columna de cada tipo es mucho más difícil de valorar.

${ }^{27}$ En el cancionero hay una mayoría de octavas. Hay tres esparsas de 9 versos: dos de Juan Álvarez Gato y una de Fernán Sánchez Talavera. Dos textos con 10 versos por estrofa: Jorge Manrique -qué cosa es amor- y Ervías -En loor de Nuestra Señora-. Solo Jorge Manrique emplea estrofas de 12 versos (Coplas a la muerte de su padre) e Íñigo de Mendoza, de 13 (Dechado y regimiento de príncipes y las Coplas a las mujeres).

${ }^{28}$ Recordemos que las rúbricas solo excepcionalmente van en letra más grande (ver notas 18 y 19). Hay muchos titulillos de grupos de estrofas, sobre todo en el poema de Virtudes y vicios de Pérez de Guzmán, lo que implica que a veces están prácticamente pegadas a los versos, y en algunos casos parecen estar fuera de la caja.

${ }^{29}$ La signatura tipográfica de cuaderno parece ir al borde de la caja pero por fuera.

${ }^{30}$ Sigo la convención establecida por Mercedes Fernández Valladares, La imprenta en Burgos (15011600), 2 vols., Madrid, Arco Libros, 2005, I, p. 120.

${ }^{31}$ Lo he podido verificar en el ejemplar escurialense y en el I-2892 de la BNE. En el otro incunable de la BNE, el I-2567, no se ha conservado el folio original, y en su lugar hay una copia manuscrita, que corrigió el error: eij

${ }^{32}$ Por ejemplo en $92 \mathrm{VC}$, cada estrofa empieza con un calderón.

${ }^{33}$ Lo que no observo en la ortografía de $86^{*} \mathrm{RL}$ es el error de poner la doble «rr» para representar la vibrante simple en posición intervocálica que sí es una característica presente en varios impresos de la segunda época de Pablo Hurus de 1492, 1493 y 1495 (por ejemplo, Çarragoça en el colofón de la Vida y tránsito de San Jerónimo, ver Mercedes Fernández Valladares, «Dos ejemplares recuperados del Cancionero de Zaragoza (92VC) con sorpresa inserta: unas desconocidas Coplas del Quicumque vult y dos nuevos fragmentos de La Pasión trovada y de la Vita Christi》, en Revista de Cancioneros Impresos y Manuscritos, 8 (2019), pp. 50-106 [58]. [En línea]. Enlace: <https://rcim.ua.es> [Consulta: 20/12/2019]. 
alternancia entre el dígrafo $n y$ y la ñ a lo largo de todo el volumen ${ }^{34}$. En el primer folio (prólogo y tabla) hay alternancia entre el signo tironiano y la conjunción $e$. En cambio, en los poemas es sistemático el uso del signo tironiano. En cuanto a la puntuación ${ }^{35}$ se observan también diferencias entre el primer folio y el resto. Así en el folio que abre el cancionero encontramos los dos puntos (:) con valor de coma, la vírgula superior [/] para separar las partes de una enumeración ${ }^{36}$, la doble rasgadura oblicua ascendente (") en la palabra inacabada de final de reglón, y el punto final. En los poemas no he visto ni el punto, ni los dos puntos, ni la doble rasgadura oblicua ascendente, dado que el verso coincide con la línea o renglón, pero sí aparece la dicha doble rasgadura en alguna de las rúbricas especialmente en las que he comentado en la nota 19. Todas las estrofas empiezan con mayúscula, pero no acaban con punto. Sí he observado en los versos el uso sistemático de la vírgula superior delante de la o disyuntiva ${ }^{37}$.

Determinadas características de $86 * \mathrm{RL}$ de un cierto arcaísmo podrían situar al Cancionero de Ramón de Llavia en el primer período de la oficina tipográfica de Pablo Hurus (hasta 1486-88 aproximadamente). Me refiero a la ausencia de foliación, de capitales de ningún tipo y, sobre todo, de colofón. Si bien es una característica habitual de los incunables hispánicos que vayan sine notis, casi todos los impresos que estampó Pablo Hurus a partir de 1477 carecen de colofón: 19 en total ${ }^{38}$, y solamente dos lo tienen y consignan el

${ }^{34}$ Ejemplos con ny: senyaladamente (f. [1r]), senyor (f. [2r]), suenyos, sonyado (f. [7r]), panyo (f. [18v]), danyaran (f. [24r]) senyalando (f. [35r]), entranyas (f. [86r]). Con ñ: señora (f. [1v]), maña (f. [13v]), peña (f. [18v]), señorios (f. [35r]), desdeñado (f. [71v]), compañia (f. [84r]), alimaña (f. [95r]).

${ }^{35}$ Sobre la puntuación ver José Manuel Blecua, «Notas sobre la puntuación española hasta el Renacimiento», Homenajes y otras labores, Zaragoza, Institución Fernando el Católico, 1990, pp. 183-187. Fidel Sebastián Mediavilla, «Itinerario de un sistema de puntuación», en Bulletin Hispanique, 114:2 (2012), pp. 937-961. Y también Alejandro Higashi, «Puntuación y lectura en la Edad Media», en Avatares y perspectivas..., II, pp. 1663-1684. Pallarés, ob. cit., p. 212, hace una referencia muy general a la puntuación de los textos impresos por los Hurus, pero lo que tiene realmente interés son las palabras del arzobispo Alonso de Aragón que recoge: «qui et libros summa cum fide: litterarum forma : punctorum distinctione : et tota scribendi arte (que orthographiae dicitur) observata : eleganter imprimi curat :...». Pertenecen al Missale secundum consuetudinem ecclesiae Cesaraugustanae, Pablo Hurus, 1485. Es probable que el corrector fuera Gonzalo García de Santa María, como lo fue de otros impresos de los Hurus en los que así consta.

${ }^{36}$ honra a tus suegros / ama tu marido / gouierna tu casa | rige tu familia / vive sin reprehension a cartas. lxv (tabla, líneas 5 y 6 , f. [1v]).

${ }^{37}$ Algunos ejemplos: si es tibia caliente / o fría (f. [2r]); que de torpe / o de honesto (f. [7r]); que aprouechan / o que danya (f. [17r]); de athenas / o de bolonia (f. [85v]), Quel fablar deue ser / o costrenido de | necessidad / o de quando hombre es preguntado (f. [18r] es una rúbrica interna); por desamparo / o cura negligente (f. [18v]); a elegir dulce / o azedo (f. [24v]); se ganan dineros / o la su valía (f. [52r]); pues por poco amor / o por negligencia (f. [62r]); por arte / o scientia / o caualleria (f. [67v]).

${ }^{38}$ Números 2, 3, 4 (con Enrique Botel) y del 5 al 21 (en solitario), a excepción del 9 (con Juan Planck). «Catálogo de incunables de Zaragoza» (Palláres, ob. cit., pp. 845-850). 
impresor (y/o editor) pero no la fecha (ambos de 1485) ${ }^{39}$. Son elementos a considerar que vendrían a corroborar la fecha más temprana de 1486 dentro del período propuesto.

He dejado para el final una característica del papel: la filigrana. Los catálogos y repertorios de incunables cuando se refieren a $86^{*} \mathrm{RL}$ aluden a la filigrana de la mano con flor, pero mi sorpresa fue la identificación de 7 manos con flor o estrella distintas, presentes todas en los 3 ejemplares madrileños. También encontré otra, especialmente rara, que podría ser un anillo. De hecho Benítez Claros la menciona y describe de esta forma «dos óvalos acéntricos, rematado el exterior por una especie de borlas» ${ }^{40}$. Aunque él pone en duda que sea del papel original, sí lo es, porque está presente en los tres ejemplares que he visto, aunque no he sido capaz de dar con ella en los repertorios clásicos de filigranas.

Todavía la identificación del papel a través de las filigranas puede permitir datar con precisión -0 por lo menos acotar en un corto espacio de tiempo-, el año de producción de un libro, de un manuscrito, e incluso puede llegar a determinar el lugar de la edición o el impresor. La labor desempeñada en este campo por Gerard van Thienen es pieza clave para conocer y poder datar las filigranas de los incunables españoles. Su base de datos Watermarks in Incunabula printed in Spain $^{41}$ recoge 6000 imágenes de filigranas, seleccionadas a partir de las 900 ediciones incunables que revisó ${ }^{42}$. La filigrana de la mano con flor o estrella es la más abundante en la documentación peninsular, especialmente en el último tercio del siglo xv, lo que ha supuesto que en los catálogos de filigranas no se haya recopilado ni una cuarta parte de las que hay ${ }^{43}$. Dicha

${ }^{39}$ Los números 22 y 23 del Catálogo (ibidem, p. 851). Se trata de los Evangelios y epístolas de todo el año, traducidas por Gonzalo García de Santa María, y el Missale secundum consuetudinem ecclesiae Cesaraugustanae.

${ }^{40}$ Ob. cit. p. XIX. También Martín Abad la ha localizado en los ejemplares de la BNE, art. cit., p. 135.

${ }^{41}$ WIES. [En línea]. Enlace: <https://bernstein.oeaw.ac.at/databases/wies/watermarks.html $>$ [Consulta: $01 / 03 / 2020]$.

${ }^{42}$ Sus frotados originales y archivo personal sobre filigranas españolas se conservan actualmente en la ciudad de Oviedo.

${ }^{43}$ De hecho en La Historia del papel en España de Oriol Valls i Subirà (Madrid, Empresa Nacional de Celulosas, 1978, 3 vols.) apenas está representada por este motivo. Huelga decir que ninguna de las filigranas de mano con flor/estrella que hay en $86^{*}$ RL están en Briquet o Piccard. Aún hay varias cuestiones que se siguen debatiendo respecto de las filigranas. (Sigo en esta exposición fundamentalmente a María del Carmen Hidalgo Brinquis, «El papel de los incunables españoles», en Isabel I y la imprenta. Consecuencias materiales, en el mundo cultural, de esta revolución tecnológica. Actas de las jornadas, Madrid, 18-20 de noviembre de 2004, Madrid, Ministerio de Cultura, 2005, pp. 298-312). Parece ser que los papeleros introdujeron la filigrana como una marca personal o de fábrica, para distinguir sus productos de la competencia, pero pronto fueron usadas como signos de procedencia, indicando no un papelero sino un molino de papel, ya que la calidad del producto no se debía únicamente a la habilidad del artesano, sino al ingenio y la situación y pureza de las aguas que lo abastecían. Por ello, cuando había varios molinos 
marca de agua se creía originaria de Génova, pero acabó siendo indicador de calidad del papel para los impresos hispánicos, vinculada directamente o no al papel fabricado en Génova ${ }^{44}$, pues esta relación filigrana-calidad del papel llevó a muchos papeleros a copiar las filigranas de mayor prestigio, para mejor comercializar sus productos. Pese a que no hay diferencias en las características materiales del papel para manuscritos o impresos, estas se hacen patentes en el estudio de su comercialización y distribución, ya que, si la tirada media de una edición contaba con 500 ejemplares, para conocer el suministro del papel sería necesario estudiar el conjunto de la edición, y así saber el grado de heterogeneidad de los fondos de materia prima de que disponía un tipógrafo. Además, para saber sus fuentes de aprovisionamiento y cuándo cambian, habría que analizar también la producción a lo largo de un arco cronológico de al menos 15 años. Del mismo modo, un análisis sincrónico de varios editores de una misma zona completaría el panorama de las fuentes de provisión ${ }^{45}$.

Para el caso de Aragón y Zaragoza en el siglo xv, están documentados papeleros oriundos de Génova, o de sus alrededores, trabajando en los molinos de la región, con la particularidad de que no eran asalariados de ningún comerciante de su república sino empresarios independientes, con obreros especializados de Génova a su cargo. Y ellos mismos vendían y comercializaban directamente su producción de papel ${ }^{46}$. Los trabajos de Janke, de Pedraza y de Pallarés ${ }^{47}$ así lo han demostrado con toda la documentación de archivo que han exhumado. Pero estos papeleros solían figurar con sus

en una misma región, se buscaba un símbolo que los representase conjuntamente. El problema se traduce en el hecho de que, generalmente, se ignora cuáles son los dibujos que identifican un molino. La relación «un dibujo-un molino» es muy aproximada ya que se ha podido constatar que un gran número de molinos europeos tenían por contraseña de su producción la cabeza de buey, el ancla, la balanza o la mano. La cabeza de buey caracteriza simultáneamente el papel fabricado en Francia, Baviera y Lombardía, áreas geográficas muy lejanas entre sí e independientes administrativamente, pero dada la permanencia de esta similitud y la falta de quejas de los fabricantes, parece ser que tal coincidencia no constituía una infracción a la exclusividad de la marca de fábrica.

${ }^{44}$ Estas consideraciones sobre el uso de la filigrana en la segunda mitad del siglo xv son válidos tanto para documentos manuscritos como impresos, pero, a su vez, estos datos se podrían enriquecer con el estudio de los incunables, cuyas filigranas en general han sido poco analizadas, ya sea por la dificultad que encierra su visión, a causa de la abundancia de la tinta impresa en ambas caras del papel, o por el desplazamiento de la misma según el formato y plegado que tenga el impreso. No sabemos si estos problemas son los que indujeron a los creadores de los grandes corpus de filigranas, como Briquet o Piccard, a centrar sus estudios en documentación de archivo, pero el estudio de las filigranas en los incunables e impresos antiguos sigue siendo una asignatura pendiente.

${ }^{45}$ Ibidem, p. 312.

${ }^{46}$ Sigo directamente a Miguel Ángel Pallarés Jiménez, «Papeleros genoveses en la Zaragoza bajomedieval», en Revista de historia Jerónimo Zurita, 67-68 (1993), p. 69.

${ }^{47} \mathrm{R}$. Steven Janke, «Algunos documentos sobre Pablo Hurus y el comercio de libros en Zaragoza a fines del siglo XV», en Príncipe de Viana, XLVII: Anejo 2 (1986), Homenaje a Don José María Lacarra, Pamplona, IPV, I, pp. 335-349. Manuel José Pedraza Gracia, La producción y distribución del libro en 
nombres más o menos hispanizados -igual que los impresores alemanes, los Chabalín (Chiavari), Jaime Mirón-, y además algunos acabaron incluso por naturalizarse y en los documentos ya no consta su lugar de origen. Entre toda esta documentación encontramos la comanda de papel que hizo Pablo Hurus, en1484, acompañado de Plank, al maestro papelero Tomás Guerços (alias Andrazo) en la ciudad de Tarazona ${ }^{48}$. Pese a lo que podría parecer, el papel de los primeros incunables españoles suele ser de fabricación autóctona pero elaborado «a la manera italiana».

En los incunables hispánicos la filigrana de la mano presenta multitud de variantes. Thienen ha clasificado 202 tipos, muchas además atípicas ${ }^{49}$. Julián Martín Abad, siguiendo la clasificación de Thienen, ha identificado en los dos ejemplares de $86^{*} \mathrm{RL}$ conservados en la BNE, las siguientes filigranas: de la sección «Mano, +»: A4 101; de «Mano, estrella / flor de 6 puntas»: A4 705, 712 y $713^{50}$. He identificado además, de la sección «Mano, estrella / flor de 5 puntas»: A4 355; y de la sección de «Mano, +»: A4 101 ${ }^{51}$. Hay otra filigrana de mano con estrella/flor de 5 puntas que no he conseguido localizar en la base de datos, y es muy peculiar, porque se caracteriza por tener cuatro dedos juntos menos el pulgar separado. Sin embargo, la he visto en una imagen de un pliego incunable conservado en la catedral de Huesca. Pliego que ha sido localizado y recuperado por M. Ángel Pallarés ${ }^{52}$. Por su letrería, Pallarés afirma que pertenece a los impresos de Enrique Botel y Pablo Hurus entre 14761477. De manera que en la página 256 del artículo de Pallarés puede verse la fotografía en la que se trasluce dicha marca de agua. Hay otra filigrana, más

Zaragoza. 1501-1521, Zaragoza, Institución Fernando el Católico, 1997. Pallarés, art. cit, pp. 65-102, y La imprenta de los incunables..., ob. cit., pp. 491-497.

${ }^{48}$ Maestro papelero que luego trabajaría en Zaragoza, Pallarés, La imprenta de los incunables..., ob. cit., p. 496 y pp. 638-639 (documento 149). El hecho de que sea el propio Hurus quien haga la gestión pone de manifiesto y corrobora que era también mercader, ya que normalmente no eran los impresores quienes compraban el papel al molino. Todavía Jorge Coci adquirió papel en un molino de Tarazona, ver Pedraza, ob. cit., p. 77. Lo que vendría a coincidir con una forma de trabajar, y parecidos usos y costumbres. De hecho Norton, ob. cit., p.120 señala que «los cambios administrativos en el taller de los Hurus no repercutieron en su material, y durante años Coci y Rosenbach fueron los únicos entre los grandes impresores de España en oponer resistencia a los tipos parisinos de última moda introducidos por Brocar».

${ }^{49}$ Tomo el dato de Gerard van Thienen, «El papel en las filigranas de los incunables impresos en España a través de los diversos ejemplares conservados en las bibliotecas del mundo», en Syntagma, 2 (2008), pp. 239-261. Ver también del mismo autor «Datación e identificación de libros impresos, manuscritos y obras de arte a través de las filigranas papeleras», en Titivillus, 1 (2015), pp. 101-119.

${ }^{50}$ «El día después...», art. cit., p. 135.

${ }^{51}$ Es la más abundante, significa que gran parte del papel con esta filigrana se empleó en la tirada de estos tres ejemplares. La reproducción de casi todas estas filigranas (calco con el sistema de frotado) puede verse en la base de datos WEIS; además Thienen empleó para dichos frotados el ejemplar escurialense.

${ }^{52}$ Miguel Ángel Pallarés Jiménez, «Otro incunable zaragozano: Monitoria para que los musulmanes de Aragón y Navarra derriben las zomas, de 1477, guardada en el archivo de la catedral de Huesca», en Argensola. Revista de Ciencias Sociales del Instituto de Estudios Altoaragoneses, 118 (2008), pp. 253-270. 
difícil de documentar aún, que es un anillo o joya, «o insignia de rango» (así la ha clasificado Thienen) que se asemeja a la designada con la referencia R27. Con frecuencia se ha dicho que no era relevante el estudio del papel de una edición porque el papel no tenía por qué coincidir en los ejemplares. En los incunables, el papel acaba siendo también marca de calidad, y aunque se surtan de distintos molinos, en determinados períodos podrían ser prácticamente los mismos. Prueba de ello es que he encontrado las mismas filigranas en los tres ejemplares que he podido analizar.

Hasta la fecha conocemos seis ejemplares conservados del Cancionero de Ramón de Llavia ${ }^{53}$ :

1. El Escorial, Biblioteca del Monasterio de San Lorenzo de El Escorial, 32-I-13 $\left(1^{\circ}\right)$. (Antigua signatura 1-Z-13) $)^{54}$. Forma parte de un volumen facticio; ocupa el primer lugar en él. Está encuadernado con la edición de las Fábulas de Esopo de Juan Hurus de 1489 (Vida del Isopet con sus fábulas historiadas $)^{55}$. Conserva la característica encuadernación escurialense renacentista, en piel con parrilla gofrada en el centro a modo de superlibros, con los cortes dorados en los que se lee 13 Fernan Perez $^{56}$, cajos rotos y zonas perdidas en tapa posterior y lomo, y puntas incompletas. En la primera hoja de guarda, en el verso, se lee centrada, escrita a mano en tinta negra con letra pequeña una antigua signatura: i-z-13. Y debajo, a lápiz de color rojo, otra signatura -la actual- de medida mucho mayor con respecto a la primera: 32I-13. Y ya en mitad de la hoja de guarda un exlibris de la Biblioteca en un

${ }^{53}$ Empiezo por los tres conservados en las bibliotecas de la Comunidad de Madrid, porque los otros aún no los he podido inspeccionar personalmente, y tampoco están digitalizados.

${ }^{54}$ [98] f.; Fol. (29 cm). Ejemplar en buen estado general de conservación, Foliación manuscrita a tinta; f. 98 casi suelto; algunas manchas de humedad; amarilleo. En el folio 8 del primer cuaderno pruebas de tinta en la parte inferior.

${ }^{55}$ Se trata de un ejemplar único. Las fábulas de Esopo han sido estudiadas por M. ${ }^{\text {a Jesús Lacarra en }}$ varios trabajos: «La fortuna del Isopete en España», en Actas del XIII Congreso Internacional AHLM (Valladolid, 15 a 19 de septiembre de de 2009). In Memoriam Alan Deyermond, ed. de J. M. Fradejas Rueda, D. Dietrick Smithbauer, D. Martín Sanz y M. J. Díez Garretas, Valladolid, Ayuntamiento-Universidad de Valladolid, 2010, vol. 1, pp. 107-134. «Fábulas y proverbios en el Esopo anotado», en Revista de poética medieval, 23 (2009), pp. 297-329. Y en colaboración con José Aragüés, «Un camino de libros. Zaragoza, Toulouse, Burgos y el texto del Ysopete», Toulouse-le Mirail, Collection Méridienne (en prensa). Ver también la historia del incunable zaragozano de Juan Hurus 1489 en la base de datos COMEDIC, Catálogo de obras medievales impresas en castellano hasta 1600. [En línea] Enlace: <http://grupoclarisel.unizar.es/comedic/> [Consulta: 13/12/2019], Zaragoza, Grupo Clarisel, Universidad de Zaragoza. La ficha concreta del incunable: <https://comedic.unizar.es/index/read/id/96>

${ }^{56} \mathrm{Al}$ respecto José Luis Checa Cremades, La encuadernación renacentista en la Biblioteca del Monasterio de El Escorial, Madrid, Ollero \& Ramos, 1998. Según ha señalado Checa era habitual encuadernar varias obras en un solo volumen porque se pretendía conseguir una buena proporción en las medidas de los libros, p. 68. 
sello de papel blanco, de reciente factura ${ }^{57}$. Conserva todos sus folios (98, con foliación arábiga en tinta negra del 1 al 97, dado que hay dos folios con el número $1^{58}$ ), aunque el último folio está casi suelto. Tiene algunas manchas de humedad en los bordes externos de los folios, sobre todo en los primeros treinta folios y el papel amarillea en algunas partes del volumen. Como consecuencia de la encuadernación, en el verso de algunos folios las primeras letras de las estrofas en arte mayor de la primera columna de texto han quedado cortadas por la cuchilla ${ }^{59}$. Anotaciones de algún poseedor: subraya los nombres de los poetas en la tabla, y marca con una cruz griega algunas estrofas que debían de interesarle por algún motivo (normalmente la cruz está en el margen de la copla, otras veces en la parte superior, en el blanco entre estrofa y estrofa). También hay algunas manchas de tinta y pruebas de pluma.

Este volumen, formado por el Cancionero de Ramón de Llavia y por la Vida del Isopete, perteneció a la reina Isabel I de Castilla. Así lo ha identificado Elisa Ruiz García ${ }^{60}$ en Los libros de Isabel la Católica ${ }^{61}$. En el Centón Epistolario de Fernan Gómez de Cibdarreal, se habla de este ejemplar ${ }^{62}$.

2. Madrid, Biblioteca Nacional de España, I-2567 (antigua signatura I-2108). Perteneció a Pascual de Gayangos ${ }^{63}$ e ingresó en la BNE en 1899 con la mayoría de libros del bibliófilo. Cuando J. Martín Abad realizó el Catálogo

\footnotetext{
${ }^{57}$ El escudo del monasterio con la parrilla de San Lorenzo en el centro. Debajo «Real Biblioteca del Monasterio» (en negrita y cursiva). Y en la línea siguiente: «28200 SAN LORENZO DE EL ESCORIAL» y debajo «MADRID-ESPAÑA».

${ }^{58}$ El primer 1 numera el folio donde está el prólogo, y el otro 1, el comienzo de las coplas. La foliación está hecha con la misma tinta y diseño que la signatura antigua.

${ }^{59}$ En la parte correspondiente a la Confesión rimada de Pérez de Guzmán, en concreto los ff. [49v-58v].

${ }^{60}$ Leí la información en Lacarra, «La fortuna del Isopete...», art. cit., p. 112.

${ }^{61}$ Arqueología de un patrimonio escrito, Salamanca, Instituto de Historia del Libro y de la Lectura, 2004. En el inventario de los libros de Isabel la Católica que fueron enviados al monasterio de El Escorial procedentes de la Capilla Real de la Catedral de Granada figuraba:

[D1 30] Iten, las Coplas de Hernand Pérez de Guzmán y las Fábulas de Ysopete con su vida, de molde, con tablas y cuero morado

[D1 40] Otro libro en rromance, ynpreso, contiene dos tratados, el uno, Coplas, hechos por Fernán Pérez de Guzmán, y el otro, Vida y Fábula de Ysopo

Ambas referencias se refieren al mismo volumen que tenía encuadernadas juntas las dos ediciones.

${ }^{62}$ Ed. cit., f. 191r-v: «Hay en el Escorial un tomo en folio impreso en bello papel, sin nombre de impresor, año, lugar, ni foliatura, que empieza así: Prólogo fecho a la señora Doña Francisquina de Bardaxi, muger del magnifico señor Mosen Juan Fernandez de Heredia, Governador de Aragon, por Ramon de Llávia. Es una coleccion de poesías de varios autores Castellanos de tiempo de D. Juan el II. D. Enrique IV, y Reyes Católicos, todas sobre asuntos morales. De Fernan Perez de Guzmán hay estas...», Benítez Claros, ob. cit., p. XXXI.

${ }^{63}$ En el primer folio, al pie, exlibris de la Biblioteca de Pascual Gayangos en tinta roja.
} 
Bibliográfico de la Colección de Incunables de la $B N E^{64}$, era el único ejemplar que había en la BNE. Méndez habla de un ejemplar que había en la Biblioteca Real ${ }^{65}$, pero no podía ser este porque en aquel momento no estaban todavía los libros de Gayangos. En cambio, el que describió Gallardo sí podría ser este ejemplar, pero lo examinó antes de que fuese adquirida por la BN la biblioteca de Gayangos ${ }^{66}$. Cuando Haebler habla de la edición de $86^{*} \mathrm{RL}$ da por desaparecido el ejemplar de la Biblioteca Real ${ }^{67}$, pues solo menciona el de El Escorial, el de la Biblioteca Imperial de Viena y el de la British Library (Salvá-Heredia). Hago este preámbulo porque el que estaba en la Biblioteca Real, que vio Méndez, debe de ser el otro ejemplar que actualmente está en la BNE (I-2892). Así lo ha explicado J. Martín Abad al ver la similitud que hay entre ambos ejemplares. Por tanto, lo que comento a continuación atañe a los dos. Encuadernación en pergamino, del siglo xIX; «coinciden las cabezadas, el jaspeado de los cortes y la técnica del encuadernador» ${ }^{68}$. Presentan hojas montadas sobre cartivanas, y han sido restauradas especialmente en los márgenes inferiores, con reconstrucción de parte del texto que no coincide exactamente con el texto original del impreso. El último de los folios ha sido encuadernado al revés.

A este ejemplar, ahora me refiero al I-2567, le faltan los folios con signaturas a1-a7, b1-b8, c1-c3 y n7, que han sido sustituidas por copias manuscritas, por imitaciones muy bien hechas, que a simple vista son difíciles de detectar, dada su perfección ${ }^{69}$. También falta la hoja signatura $n 8$ sustituida por una reproducción fotolitográfica. Martín Abad concluye que la restauración de este ejemplar ha sido hecha teniendo a la vista el otro ejemplar custodiado hoy en la BNE. Pero ambos ejemplares no coinciden exactamente en el texto de los márgenes inferiores deteriorados, porque este ejemplar fue suficientemente

\footnotetext{
${ }^{64}$ Publicado en 2010. Sigo a grandes rasgos su descripción, ob. cit., C-24, p. 223. Y también los datos que aporta sobre este incunable en «El día después...», art. cit., pp. 131-139 (Título del apartado: 1. La edición incunable del «Cancionero» de Ramón de Llavia: de un nuevo ejemplar y de otro que ha devenido cierta y peligrosamente impuro).

${ }^{65}$ Después será la Biblioteca Nacional.

${ }^{66}$ Martín Abad señala que Gallardo incorporó a su noticia bibliográfica sobre el ejemplar B.-Gámez, cuando en realidad lo que quiso escribir fue $B$. G. (como solía indicar que era de Gayangos), art. cit., p. 123.

${ }^{67}$ En la Segunda parte de la Bibliografía ibérica del siglo $\mathrm{x} V$, Haebler ya recoge el ejemplar de Gayangos.

${ }^{68} \mathrm{~J}$. Martín Abad, art. cit., p. 135.

${ }^{69}$ Es en las letras mayúsculas donde veo un poco más de tinta que en la impresión que deja un tipo, pero porque lo sé (hay que fijarse). Además quien hizo la falsificación, como ha señalado Martín Abad (ibidem), tenía a mano papel antiguo del siglo xv. Ese papel parece más oscuro, y al tacto, un poco más grueso, casi imperceptible.
} 
manipulado haciéndolo pasar por una edición distinta ${ }^{70} \mathrm{y}$ así obtener mayor beneficio económico ${ }^{71}$.

Este ejemplar con folios (y fragmentos de texto) falsificados es el que empleó Rafael Benítez Claros para su edición, aun cuando él dice que la realizó a partir de los ejemplares de El Escorial y de la BN (el mútilo de la Biblioteca de Gayangos era el que había en 1945), pero en verdad apenas usó el texto del escurialense. Julián Martín Abad ha realizado unas calas en el texto de la edición de Benítez Claros y queda patente que no sólo se basó fundamentalmente en el texto de I-2567, sino también en Foulché Delbosc ${ }^{72}$, e incluso en ediciones postincunables de Las setecientas de Pérez de Guzmán ${ }^{73}$. Por tanto, no hay que fiarse de dicha edición, y quienes lo hayan hecho tendrán que revisar su trabajo. Es mejor recurrir al cancionero original en un ejemplar fiable que a la edición de Benítez Claros.

3. Madrid, Biblioteca Nacional de España, I-2892. Adquirido a Guillermo Blázquez Librería de libros antiguos (Madrid), en 2010. Está completo, tiene los 98 folios pero la parte inferior de los folios está muy estropeada, y han desaparecido gran parte de las signaturas tipográficas. Conserva foliación moderna, pero medio cortada por la encuadernación. El penúltimo folio está encuadernado al revés, como ya se ha dicho. Conserva marcas de algún poseedor indicando la palabra no en el margen de algunas estrofas, bien por no ser el orden correcto o porque no pertenecen al poema ${ }^{74}$. Otras anotaciones han sido borradas ${ }^{75}$.

${ }^{70}$ Veamos algunos ejemplos. F. [91r], (4 últimos versos columna b); texto original: lo que deuo $\mid n i$ merezco yo llegar $\mid$ a gastarme en le seruir $\mid$ mas de nueuo

Texto falsificado: lo que decir $\mid$ ni menos poder fablar $\mid$ a quien no deseo mentir $\mid$ ni seruir

F. [95v], (3 últimos versos columna a); texto original: el hombre crudo espantoso | mata sus mismas naciones $\mid$ \& encadena

Texto falsificado: \& el hombre crudo \& vicioso $\mid$ mata sus mesmas naciones $\mid$ sin cadena

${ }^{71}$ Esto sucede precisamente en los folios finales del ejemplar. Mercedes Fernández Valladares, a quien agradezco la observación, me comentó que muchas veces se manipula el texto en dicha parte del libro porque el comprador es una de las que suele mirar.

${ }^{72}$ Raymond Foulché-Delbosc, Cancionero castellano del siglo XV, Madrid, Bailly-Baillière, 1912 1915, 2 vols. De Foulché-Delbosc tampoco conviene fiarse demasiado, porque para algunos autores copió directamente -sin mencionarlo- del libro de Eugenio de Ochoa, Rimas inéditas de Don Íñigo López de Mendoza, Marqués de Santillana, de Fernán Pérez de Guzmán, Señor de Batres y de otros poetas del siglo $X V$, París, Fain y Thunot, 1844. Y Ochoa no fue un buen editor, creando a veces versos inexistentes al combinar la mitad de un verso de un testimonio con medio verso de otro testimonio, de los cancioneros castellanos que tenía a su alcance, los de París (BNF).

${ }^{73}$ Ver el muestrario comparativo que ofrece Martín Abad (art. cit., pp. 138-139), pues la manipulación del texto que realizó Benítez Claros afecta al menos a 28 páginas.

${ }^{74} \mathrm{~F}$. [20r], ciiij, canceladas las coplas 2, 3, 4 de la primera columna y la 1 de la segunda.

${ }^{75}$ Por ejemplo en el folio [16], no se aprecia lo que ponía, pero se ve claramente que lo han limpiado. 
4. London, British Library, IB.52163. Pasó a formar parte de sus fondos en julio de 1892 cuando fue adquirido en París en la subasta de la biblioteca de Ricardo Heredia. Es el ejemplar que perteneció a Salvá. Conserva una de las características encuadernaciones de la biblioteca de Salvá (de tipo imperio, en piel verde, marroquín) con adornos dorados y el superlibros de la Biblioteca Salvá. Con el monograma de Heredia. Está completo y en buen estado de conservación. Con foliación manuscrita.

5. Wien, Österreichische Nationalbibliothek, INK 18.C.18. Probablemente proceda de la rica biblioteca de la Casa de Habsburgo, cuyos fondos se remontan a la Edad Media y se custodian actualmente en la Biblioteca Nacional de Viena (antes de 1920, Biblioteca Imperial). Con el enlace al Gesamtkata$\log$ se accede a la ficha manuscrita de Haebler para el Typenrepertorium ${ }^{76}$. Con los 98 folios, y en buen estado.

6. Paris, Bibliotheque Nationale, RES-YG-14. 98 folios, completo. Según el catálogo de la BNF no está identificado como un incunable zaragozano de la oficina tipográfica de Pablo Hurus.

\section{Estructura}

En este apartado presentaré la descripción interna de $86 * \mathrm{RL}$ de manera que pueda ser útil como punto de partida para estudios posteriores, de ahí la presentación en un cuadro de los poemas que integran el Cancionero, con referencia a los testimonios conservados. El estudio de la selección de poemas y la relación de $86 * \mathrm{RL}$ con otros cancioneros incunables y postincunables los presentaré en trabajos futuros. Previamente me referiré al primer folio que contiene el prólogo en prosa y la tabla

f. 1r [rúbrica de la epístola dedicatoria] Prologo fecho a la Señora doña francisquina de $\mid$ bardaxi mujer del magnifico señor mossen joan fer $\mid$ nandez de heredia gouernador de aragon por ra// | mon de llabia en que le endereça el presente libro.

[incipit ]No es cosa nueua muy magnifica : \& virtuosa señora si bien [explicit] e quedo besando las manos de vuestra merced.

[rúbrica] Tabla del presente libro

[incipit ] Coplas de fernan perez de guzman de vicios : de virtudes : e

${ }^{76}$ En esta ficha es donde he visto que había un ejemplar en la Biblioteca Nacional de París. 
f. 1v [explicit de la tabla] sobre la vida venidera a cartas .xcj .

[rúbrica final de la tabla, y del folio] Son las obras en el presente | volumen contenidas. xviiij

La tabla nos desgrana los títulos de los poemas con indicación de su autor, y además puede considerarse un auténtico índice porque señala los folios de inicio de cada uno de los textos mediante la fórmula «a cartas». No hay ni una sola errata en la numeración que indica de cada texto. Pero hay que explicar que si observamos el cuadro que presento, hay 24 composiciones en el libro, pero las entradas de la tabla son 19. La diferencia estriba en que algunas rúbricas incluyen más de un poema. Por ejemplo, en la rúbrica 10 se habla de dos esparsas - dos poemas-, por tanto, en el listado de textos que he elaborado del cancionero, la entrada de la rúbrica se desdobla en dos y, así, para un texto único de la tabla habrá 2 poemas. En otros casos, como la primera obra de Pérez de Guzmán, ya es una cuestión de interpretación. Los poemas 2 y 3 que he indicado, en verdad formaban un todo con las Coplas de vicios $y$ virtudes, aunque posteriormente, alguno se desgajara, pero en los testimonios más antiguos no hay duda del conjunto. Además, en la rúbrica ya dice «vicios \& virtudes \& ciertos himnos de nuestra senyora», los ciertos himnos son dos, por tanto tenemos una sola rúbrica en la tabla para tres textos. La continuación de Gómez Manrique de Los siete pecados mortales de Juan de Mena tampoco está explicitada en la rúbrica de la tabla, seguramente porque se percibía como un todo, pues es una «continuación» (pasa igual en otros cancioneros). De manera que, en realidad, no veo ningún error en la tabla, es un reflejo fiel a lo que en su momento interpretaban; quienes lo vemos y percibimos de manera distinta somos nosotros. 


\section{Apéndice}

Mi punto de partida para la elaboración de este cuadro siempre ha sido y es El cancionero del siglo $X V$ de Brian Dutton: su trabajo ingente nos sirve para poder ir un poco más allá. Van apareciendo testimonios nuevos, ediciones que se creían perdidas se encuentran. He incorporado al cuadro los datos sobre la primera edición sevillana de las Coplas de Fernán Pérez de Guzmán, la de Ungut y Polono, 1492) que he localizado; así como los de 92VC, a partir del trabajo enriquecedor de Mercedes Fernández Valladares (art. cit.), y pudiendo consultar el ejemplar custodiado hoy en la BNE, y ya digitalizado. También las descripciones codicológicas de Manuel Moreno y de M. Jesús Díez Garretas incorporadas a CIM, grupo de investigación que dirige Josep Lluís Martos, nos aportan conocimiento y abren nuevas perspectivas. Y el proyecto dirigido por Dorothy S. Severin An Electronic Corpus of 15th Century Castilian Cancionero Manuscripts; y por supuesto, Philobiblon, con Charles B. Faulhaber a la cabeza. Si hay errores, la responsabilidad será solo mía.

\begin{tabular}{|c|c|c|c|c|}
\hline $\begin{array}{l}\text { N.\% } \\
\text { FOLIOS }\end{array}$ & ID Y AUTOR & $\begin{array}{l}\text { INCIPIT / } \\
\text { EXPLICIT }\end{array}$ & RÚBRICAS & OTROS TESTIMONIOS \\
\hline $\begin{array}{l}1 \\
{[2 r-33 v]}\end{array}$ & $\begin{array}{l}\text { 0072 F. Pérez } \\
\text { de Guzmán } \\
(497 \times 8) \\
446 \text { coplas sin } \\
\text { contar ID } 4340 \\
\text { ni ID0073, los } \\
\text { himnos a los } \\
\text { que alude la } \\
\text { rúbrica }\end{array}$ & $\begin{array}{l}\text { Amigo sabio \& } \\
\text { discreto } \\
\ldots \ldots . \\
\text { a la tu } \\
\text { magnificencia }\end{array}$ & $\begin{array}{l}\text { Coblas fechas por } \\
\text { fernan perez de } \\
\text { guzman de | vicios } \\
\& \text { virtudes: \& ciertos } \\
\text { ymnos de nuestra } \\
\text { senyora } \\
\text { [Tabla-1] Coplas } \\
\text { de fernan perez de } \\
\text { guzman de vicios: e } \\
\text { virtudes: | e ciertos } \\
\text { hymnos de nuestra } \\
\text { señora dirigidas al } \\
\text { muy magni | fico } \\
\text { : \& virtuoso aluar } \\
\text { garcia de sancta maria } \\
\text { coronjsta del | rey don } \\
\text { joan de castilla : \& de } \\
\text { su consejo . a cartas } \\
\text {.ij . }\end{array}$ & 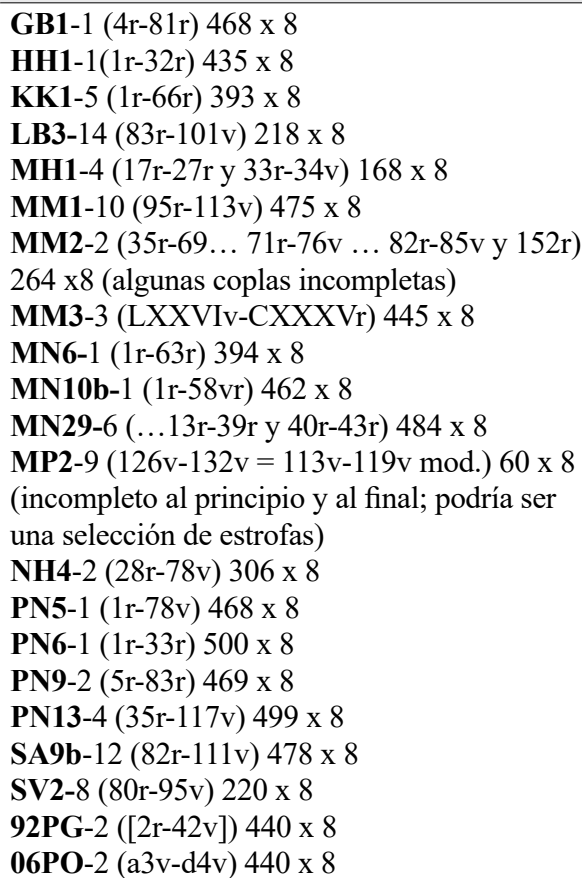 \\
\hline
\end{tabular}




\begin{tabular}{|c|c|c|c|c|}
\hline $\begin{array}{l}\mathbf{2} \\
{[29 v-30 v]}\end{array}$ & 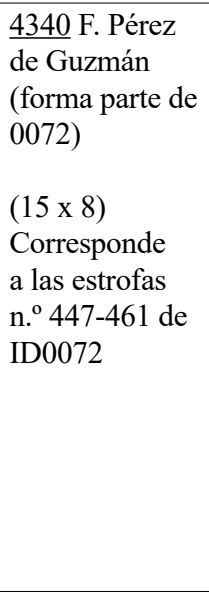 & $\begin{array}{l}\text { Como al princi- } \\
\text { pio del dia } \\
\ldots \ldots . . \\
\text { o christe sol } \\
\text { iusticie }\end{array}$ & $\begin{array}{l}\text { De loores diuinos | a } \\
\text { los maytines } \\
\text { [Tabla-1] Coplas } \\
\text { de fernan perez de } \\
\text { guzman de vicios: e } \\
\text { virtudes: | e ciertos } \\
\text { hymnos de nuestra } \\
\text { señora dirigidas al } \\
\text { muy magni | fico } \\
: \text { \& virtuoso aluar } \\
\text { garcia de sancta maria } \\
\text { coronjsta del | rey don } \\
\text { joan de castilla : \& de } \\
\text { su consejo . a cartas } \\
\text {.ij . }\end{array}$ & $\begin{array}{l}\text { GB1-2 }(76 \mathrm{v}-79 \mathrm{r} \\
\text { HH1-1Y (30r-31r) } \\
\text { MM1-10Y (112v-113r) } \\
\text { MM3-4 (CXXXVr-CXXXVJr) } \\
\text { MN29-5A (39r-40v) } \\
\text { NH4-1 }{ }^{\text {is }}(46 \mathrm{v}-49 \mathrm{r}) \\
\text { SA9b-13 (112r-115r) } \\
\text { 92PG-5 ([56v-57v]) } \\
\text { 06PO-5 (e4r-v) }\end{array}$ \\
\hline $\begin{array}{l}\mathbf{3} \\
{[31 v-33 r]}\end{array}$ & 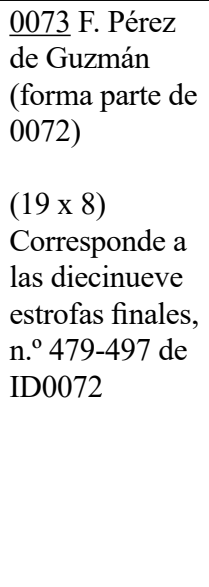 & $\begin{array}{l}\text { Virge } n \text { que } \\
\text { fueste criada } \\
\text {...... } \\
\text { a la tu } \\
\text { magnificencia }\end{array}$ & $\begin{array}{l}\text { Hymno a los gozos | } \\
\text { de nuestra senyora } \\
\text { [Tabla-1] Coplas } \\
\text { de fernan perez de } \\
\text { guzman de vicios: e } \\
\text { virtudes: | e ciertos } \\
\text { hymnos de nuestra } \\
\text { señora dirigidas al } \\
\text { muy magni | fico } \\
: \text { \& virtuoso aluar } \\
\text { garcia de sancta maria } \\
\text { coronjsta del | rey don } \\
\text { joan de castilla : \& de } \\
\text { su consejo . a cartas } \\
\text {.ij . }\end{array}$ & $\begin{array}{l}\text { B1-3 (82r-85r) } \\
\text { HH1-2 (32v-33v) } \\
\text { MM1-11 (113v-114r) } \\
\text { MM3-5 (pp. 259-263) } \\
\text { MN6a-2 (63r-66v) } \\
\text { MN10b-3 (58v-61r) } \\
\text { PN9-3 (83r-86r) } \\
\text { SA9b-14(115v-117r) } \\
\text { 92PG-6 ([57v]) 2 x } 8 \\
\text { 06PO-6 (e4v-e5r) 2 x } 8\end{array}$ \\
\hline
\end{tabular}


MATERIALIDAD Y ESTRUCTURA DE UN TEMPRANO CANCIONERO COLECTIVO INCUNABLE (86*RL)

\begin{tabular}{|c|c|c|c|c|}
\hline $\begin{array}{l}4 \\
{[33 r-39 v]}\end{array}$ & $\begin{array}{l}\frac{0100}{\text { Mena }} \text { Juan de } \\
(106 \times 8)\end{array}$ & $\begin{array}{l}\text { Canta tu chris- } \\
\text { tiana musa } \\
\ldots . . . \\
\text { ser perdonado } \\
\text { su vicio }\end{array}$ & $\begin{array}{l}\text { Los siete pecados } \mid \\
\text { mortales que fizo | } \\
\text { Johan de mena } \\
\text { [Tabla-2] De los .vij. } \\
\text { peccados mortales } \\
\text { que fizo joan de mena } \\
\text { para | la emienda de } \\
\text { la presente vida . a } \\
\text { cartas .xxxiij . }\end{array}$ & 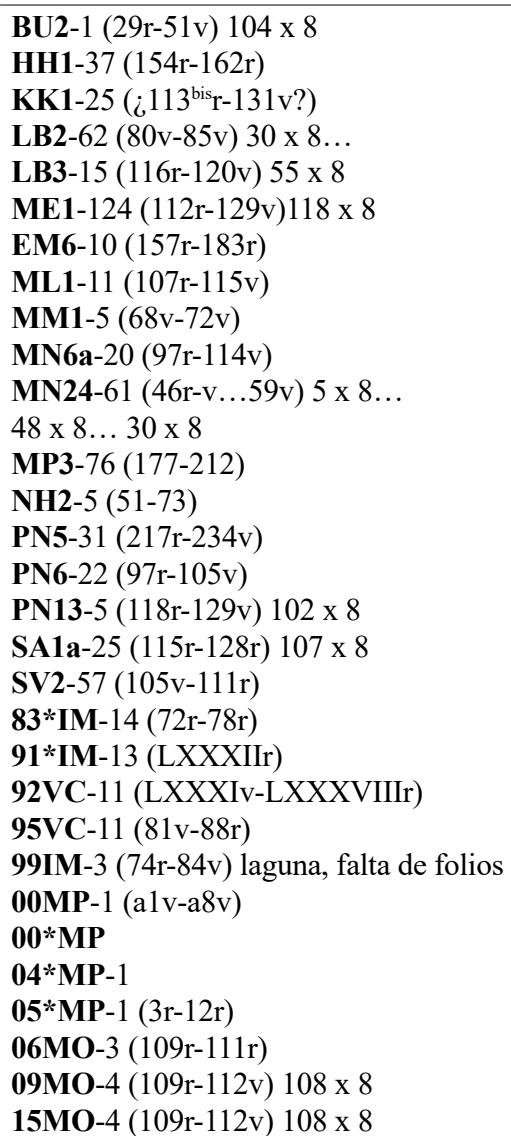 \\
\hline
\end{tabular}




\begin{tabular}{|c|c|c|c|c|}
\hline $\begin{array}{l}\mathbf{5} \\
{[39 \mathrm{v}-49 \mathrm{r}]}\end{array}$ & 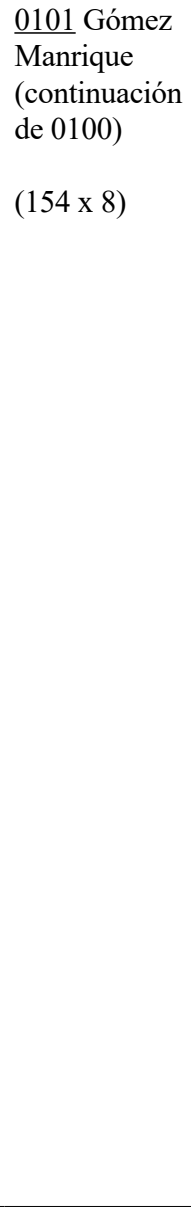 & $\begin{array}{l}\text { Pues este negro } \\
\text { morir } \\
\ldots \ldots . . \\
\text { lo que fizo cada } \\
\text { qual } \\
\text { [rúbrica final] } \\
\text { Fin }\end{array}$ & $\begin{array}{l}\text { Aqui fallecio Johan } \\
\mid \text { de mena \& por } \\
\text { fallecimiento su } \mid \\
\text { yo prosigue gomez } \\
\text { manrique \& | faze vn } \\
\text { breue prohemio en } \\
\text { esta | obra començada } \\
\text { por johan de | mena \& } \\
\text { acaba se por el } \\
\\
\text { [Tabla-2. En la } \\
\text { tabla no figura la } \\
\text { continuación de } \\
\text { Gómez Manrique } \\
\text { pero sí está } \\
\text { diferenciada esta } \\
\text { parte con una rúbrica } \\
\text { especial que ocupa el } \\
\text { mismo espacio que el } \\
\text { de una estrofa] }\end{array}$ & 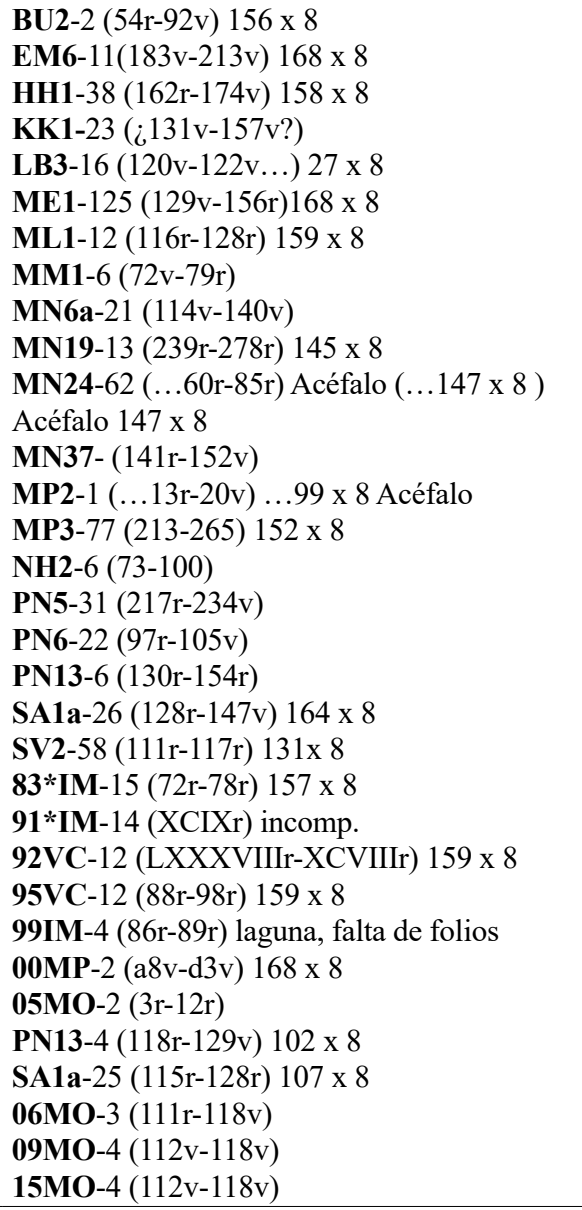 \\
\hline $\begin{array}{l}\mathbf{6} \\
{[49 v-61 r]}\end{array}$ & $\begin{array}{l}\frac{2903}{\text { de Guzmárez }} \\
(189 \times 8)\end{array}$ & $\begin{array}{l}\text { Yo pecador } \\
\text { a dios me } \\
\text { confiesso } \\
\ldots \ldots . \\
\text { sean mis yerros } \\
\text { de ti perdonados }\end{array}$ & $\begin{array}{l}\text { Confession rimada } \\
\text { por fer// | nan perez de } \\
\text { guzman } \\
\text { [Tabla-3] Confession } \\
\text { de fernan perez de } \\
\text { guzman de los .x . } \\
\text { manda// | mientos } \\
\text { : e . vij . peccados } \\
\text { mortales : e las . } \\
\text { vij . obras de mise | } \\
\text { ricordia temporales : e } \\
\text { otras . vij .spirituales a } \\
\text { car. xlviiij }\end{array}$ & $\begin{array}{l}\text { MM1-7 (79r-89v) } 188 \times 8 \\
\text { MM2-1(1r-34r, foliación propia, independien- } \\
\text { te del resto del códice) } \\
\text { MM3*-2 (pp. 100-147) } \\
\text { MN68*-(139r-167v) } \\
\text { 92PG-7 ([58r-83r]) } 152 \times 8 \text { (desorden en las } \\
\text { coplas respecto a la tradición manuscrita) } \\
\text { 06PO-7 (e5r-f6r) } 152 \times 8 \text { (desorden en las } \\
\text { coplas respecto a la tradición manuscrita) }\end{array}$ \\
\hline
\end{tabular}


MATERIALIDAD Y ESTRUCTURA DE UN TEMPRANO CANCIONERO COLECTIVO INCUNABLE (86*RL)

\begin{tabular}{|c|c|c|c|c|}
\hline $\begin{array}{l}7 \\
{[61 r-65 r]}\end{array}$ & $\begin{array}{l}\frac{6003}{\text { F. Pérez }} \text { de Guzmán } \\
(62 \times 8)\end{array}$ & $\begin{array}{l}\text { Algunos son } \\
\text { que non bien } \\
\text { opinando } \\
\text {..... } \\
\text { quien mucho } \\
\text { fabla \& non } \\
\text { miente }\end{array}$ & $\begin{array}{l}\text { Contra los que dizen } \\
\text { que di | os en este } \\
\text { mundo njn da bien } \\
\text { por bien | nin mal por } \\
\text { mal } \\
\text { [Tabla-4] Del mismo } \\
\text { fernan perez contra } \\
\text { los que dizen que dios } \\
\text { en | este mundo ni da } \\
\text { bien por bien : ni mal } \\
\text { por mal a cartas . lxj }\end{array}$ & BU2-6 (146r-160r) 57 x 8 \\
\hline $\begin{array}{l}\mathbf{8} \\
{[65 r-69 r]}\end{array}$ & $\begin{array}{l}\text { 1938 F. Pérez } \\
\text { de Guzmán } \\
(69 \times 8) \\
\text { (Sin las } 5 \text { reglas } \\
\text { iniciales que } \\
\text { presentan casi } \\
\text { todos los demás } \\
\text { testimonios) }\end{array}$ & $\begin{array}{l}\text { Muy nobles } \\
\text { señoras a vos se } \\
\text { dirige } \\
\ldots \ldots . . \\
\text { sin reprehensio } \\
\text { dezir se podria }\end{array}$ & $\begin{array}{l}\text { Coplas fechas por } \\
\text { fernan pe// | rez de } \\
\text { guzman diregidas a } \\
\text { las nobles | mujeres } \\
\text { para su doctrina } \\
\text { [Tabla-5] Del mismo } \\
\text { fernan perez dirigidas } \\
\text { a las nobles \& } \\
\text { virtuosas | mujeres } \\
\text { para su doctrina } \\
\text { dando les .v. consejos } \\
\text { los quales | son honra } \\
\text { tus suegros / ama tu } \\
\text { marido / gouierna tu } \\
\text { casa | rige tu familia / } \\
\text { vive sin reprehension } \\
\text { a cartas . lxv }\end{array}$ & $\begin{array}{l}\text { HH1-23 (73v-78r) } \\
\text { MN9-1 (1v) (7x8, extracto) } \\
\text { MP2-87 (118v-125r) } \\
\text { MN68*-2 (167v-178r) } \\
\text { MRE1-5 (212v-216v) } 26 \times 8 \text {, falta de folios } \\
\text { SA12-2 (65r-75v) 5, 63 x 8, falta de folio } \\
\text { SM4-1 1-27) 63 x 8, copia de SA12 } \\
\text { 92PG-8 ([83v-94r]) } 63 \times 8 \\
\text { 06PO-8 (66v-70v) } 63 \times 8\end{array}$ \\
\hline $\begin{array}{l}9 \\
{[69 v-73 r]}\end{array}$ & $\begin{array}{l}\underline{0273} \text { Íñigo de } \\
\text { Mendoza } \\
(37 \times 13,5 \\
5 \times 13) \\
\text { Dutton consi- } \\
\text { dera las cinco } \\
\text { últimas estrofas } \\
\text { una adición }\end{array}$ & $\begin{array}{l}\text { Alta reyna } \\
\text { esclarecida } \\
\ldots \ldots . . \\
\text { pues lo reman } \\
\text { sus estremos }\end{array}$ & $\begin{array}{l}\text { Dechado \& } \\
\text { regimiento de } \\
\text { principes | fecho } \\
\text { por fray ynigo de } \\
\text { mendoça a | la señora } \\
\text { reyna de castilla \& } \\
\text { daragon } \\
\text { [Tabla-6] Dechado } \\
\& \text { regimiento de } \\
\text { principes fecho } \\
\text { por fray ynygo | de } \\
\text { mendoça dirigido } \\
\text { a la serenissima \& } \\
\text { muy alta señora doña } \\
\text { | ysabel reyna de } \\
\text { castilla y de aragon a } \\
\text { cartas . lxiiij }\end{array}$ & $\begin{array}{l}\text { EM6-9 (146r-156r) } \\
\text { HH1-68 (400r-405r) } 40 \text { x } 13 \\
\text { MN19-78 (433r-449v) } \\
\text { SA4-16 (137r-166r) } 37 \text { x } 13 \\
\text { 83*IM-5 (42v-46r) } \\
\text { 90*IM (XLVIIv) } \\
\text { 99IM-10 (103v-106v) laguna por falta del } \\
\text { folio } 105 \\
\text { 00FPulgar 35 (91r) }\end{array}$ \\
\hline
\end{tabular}




\begin{tabular}{|c|c|c|c|c|}
\hline $\begin{array}{l}10 \\
{[73 r-76 r]}\end{array}$ & $\begin{array}{l}\frac{0277}{\text { Manrique }} \\
(40 \times 12)\end{array}$ & $\begin{array}{l}\text { Recuerde el } \\
\text { alma dormida } \\
\text {...... } \\
\text { su memoria }\end{array}$ & $\begin{array}{l}\text { De don jorge } \\
\text { manrrique | por la } \\
\text { muerte de su padre } \\
\text { [Tabla-7 ] Obra de } \\
\text { don jorge manrique } \\
\text { por la muerte } \\
\text { de su padre en | } \\
\text { menosprecio del } \\
\text { mundo a cartas . lxxiij }\end{array}$ & $\begin{array}{l}\text { EM6-15 (215v-225v) } \\
\text { HH1-79 (421v-424v...) 34 x } 12 \\
\text { LB3-5 (15r-20v...) 39 x 12, 4) } \\
\text { MN19-67 (407r-418r) 31 x 12, acéfalo } \\
\text { MP2-199 (211r-215r) } \\
\text { 82*IM-3 (x1r-x4v) } \\
\text { 82*JM-1 (1r-4v) } \\
\text { 83*IM-12 (67r-70r) } \\
\text { 90*IM (LXXVIv ...LXXXr) } \\
\text { 92VC-15 (CIXr-CXIIr) } \\
\text { 95VC-15 (109r-112r) } \\
\text { 94JM } \\
\text { 99IM-7 (92v-102r) } \\
\text { 01JM-1 (3r-20r) } \\
\text { 15*JM-1 (1r-4r) }\end{array}$ \\
\hline $\begin{array}{l}11 \\
{\left[76^{r}-78^{r}\right]}\end{array}$ & $\begin{array}{l}\frac{0271}{\text { Mendínigo de }} \\
(24 \times 12)\end{array}$ & $\begin{array}{l}\text { En este mundo } \\
\text { diforme } \\
\ldots \ldots \\
\text { a los hombres } \\
\text { bestias atan }\end{array}$ & $\begin{array}{l}\text { Coplas de fray yni | } \\
\text { go a las mujeres } \\
\text { [Tabla-8] Coplas } \\
\text { de fray ynygo de } \\
\text { mendoça a las } \\
\text { mujeres en loor de } \\
\text { | las virtuosas \& } \\
\text { reprehension de las } \\
\text { que no son tales a car. } \\
\text { lxxiij. }\end{array}$ & 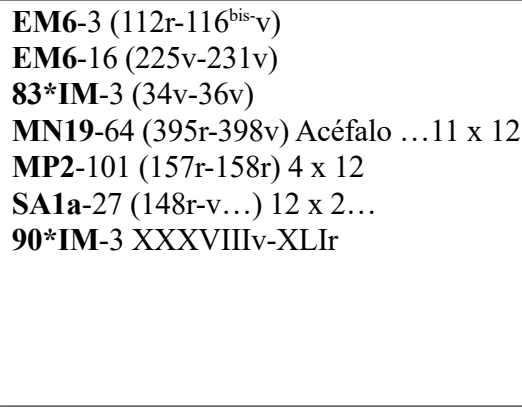 \\
\hline $\begin{array}{l}12 \\
{[78 r-78 v]}\end{array}$ & $\begin{array}{l}\frac{0276}{\text { Manrique }} \text { Jorge } \\
(5 \times 10)\end{array}$ & $\begin{array}{l}\text { Es amor fuerça } \\
\text { tan fuerte } \\
\ldots \ldots . \\
\text { el falso sobre } \\
\text { dorado }\end{array}$ & $\begin{array}{l}\text { Coplas de don jorge } \\
\text { manri | que / que cosa } \\
\text { es amor } \\
\text { [Tabla-9] Otra obra de } \\
\text { don jorge manrique } \\
\text { dando diffinicion de } \\
\text { amor | que cosa es a } \\
\text { cartas . lxxviij. }\end{array}$ & $\begin{array}{l}\text { EM6-14 }(214 \mathrm{r}-215 \mathrm{r}) \\
\text { OA1-10 (72v) } \\
\text { 83*IM-18 (87v) } \\
\text { 90*IM-17 ( XCIX-XCIX) } \\
\text { 11CG-192 (98r) } \\
\text { 14CG-214 (75v) }\end{array}$ \\
\hline $\begin{array}{l}\mathbf{1 3} \\
{[78 \mathrm{v}]}\end{array}$ & $\begin{array}{l}\frac{3130}{\text { Álvarez Guan }} \\
\left(\begin{array}{l}1 \times 9\end{array}\right)\end{array}$ & $\begin{array}{l}\text { Mundo quien } \\
\text { discreto fuere } \\
\ldots \ldots \\
\text { lo que contigo } \\
\text { non puedo }\end{array}$ & $\begin{array}{l}\text { Espara de joan aluarez } \\
\text { que } \mid \text { se despide del } \\
\text { mundo } \\
\text { [Tabla-10] Otras } \\
\text { dos esparças de joan } \\
\text { aluarez en la vna se } \\
\text { despide } \mid \text { del mundo } \\
: \text { \& la otra faze por } \\
\text { vnos compases que } \\
\text { trahia el } \mid \text { duque de } \\
\text { alua a cartas . Ixxviij. }\end{array}$ & $\begin{array}{l}\text { MH2-68 (60r) } \\
\text { 11CG-243 (111r) } \\
\text { 14CG-252 (86r) }\end{array}$ \\
\hline
\end{tabular}


MATERIALIDAD Y ESTRUCTURA DE UN TEMPRANO CANCIONERO COLECTIVO INCUNABLE ( $86^{*}$ RL)

\begin{tabular}{|c|c|c|c|c|}
\hline 14 [78v] & $\begin{array}{l}\frac{6004}{\text { Álvarez Gan }} \\
\left(\begin{array}{l}1 \times 9\end{array}\right)\end{array}$ & $\begin{array}{l}\text { El compassar es } \\
\text { medir } \\
\ldots \ldots . . . \\
\text { Que rige \& } \\
\text { manda natura }\end{array}$ & $\begin{array}{l}\text { Otra del mismo a } \\
\text { vnos com// | passes } \\
\text { que traya el duque } \\
\text { dalua } \\
\text { [Tabla-10] Otras } \\
\text { dos esparças de joan } \\
\text { aluarez en la vna se } \\
\text { despide | del mundo } \\
\text { : \& la otra faze por } \\
\text { vnos compases que } \\
\text { trahia el | duque de } \\
\text { alua a cartas . lxxviij. }\end{array}$ & $\begin{array}{l}\text { 11CG-244 (111r) } \\
\text { 14CG-253 (86r) }\end{array}$ \\
\hline $\begin{array}{l}15 \\
{[79 r-80 v]}\end{array}$ & $\begin{array}{l}\underline{1808} \text { Juan de } \\
\text { Mena } \\
\text { Adición de } \\
0092 \\
(27 \times 8)\end{array}$ & $\begin{array}{l}\text { La flaca bar- } \\
\text { quilla de mjs } \\
\text { pensamientos } \\
\ldots . . . \\
\text { que non ay cada } \\
\text { dia lugar de } \\
\text { perdones }\end{array}$ & $\begin{array}{l}\text { Comjença la muy } \\
\text { excellente obra } \\
\text { lla// | mada la flaca } \\
\text { barquilla \&c. } \\
\\
\text { [Tabla-11] Obra } \\
\text { de joan de mena } \\
\text { jntitulada la flaca } \\
\text { barquilla de mis | } \\
\text { pensamientos a cartas } \\
\text {.lxxviiij. }\end{array}$ & $\begin{array}{l}\text { SA5-4 (206v) } 3 \text { x } 8 \\
\text { SM1-6 }(29 v \ldots \text { falta el texto) } \\
\text { SA10b-143 }(147 \mathrm{v} \ldots) 2 \text { × } 8 \ldots \\
\text { 96ML-2 (f4v) } 3 \text { x } 8 \text { (sin rúbrica) }\end{array}$ \\
\hline $\begin{array}{l}16 \\
{[80 v-84 v]}\end{array}$ & $\begin{array}{l}\underline{0090} \text { F. Pérez } \\
\text { de Guzmán } \\
(2+65 \times 8) \\
\text { En } 86^{*} \mathrm{RL}, \text { hay } \\
\text { dos estrofas } \\
\text { iniciales, que } \\
\text { pertenecen a } \\
\text { otro poema } \\
\text { también dedica- } \\
\text { do al Marqués } \\
\text { de Santillana } \\
\text { en BU2 (8717). } \\
\text { Tal como está } \\
\text { en el resto de } \\
\text { testimonios } \\
\text { el texto de la } \\
\text { Coronación } \\
\text { comenzaría en } \\
\text { la estrofa } 3 \text { de } \\
\text { 86*RL (que } \\
\text { incorpora una } \\
\text { rúbrica Prosi- } \\
\text { gue la materia } \\
\text { que precede a } \\
\text { dicha copla } 3 \text { ) }\end{array}$ & $\begin{array}{l}\text { Muy amado } \\
\text { señor mio } \\
\text { (precedido } \\
\text { de la rúbrica) } \\
\text { Introduction } \\
\overline{\text { Si non mengaña }} \\
\text { el affecto } \\
\text { (v. } 8 \text { en } 86 * \mathrm{RL}, \\
\text { incipit sin contar } \\
\text { las dos coplas } \\
\text { introductorias) } \\
\text {..... } \\
\text { a todos vos } \\
\text { encomjendo }\end{array}$ & $\begin{array}{l}\text { Coronacion de las } \\
\text { quatro virtudes } \mid \\
\text { cardinales de fernan } \\
\text { perez de guzman } \\
\text { [Tabla-12] } \\
\text { Coronacion de } \\
\text { las .iiij. virtudes } \\
\text { cardinales fecha por } \\
\text { fernan } \mid \text { perez de } \\
\text { guzman endereçada al } \\
\text { marques de santillana } \\
\text { a cartas .lxxx. }\end{array}$ & 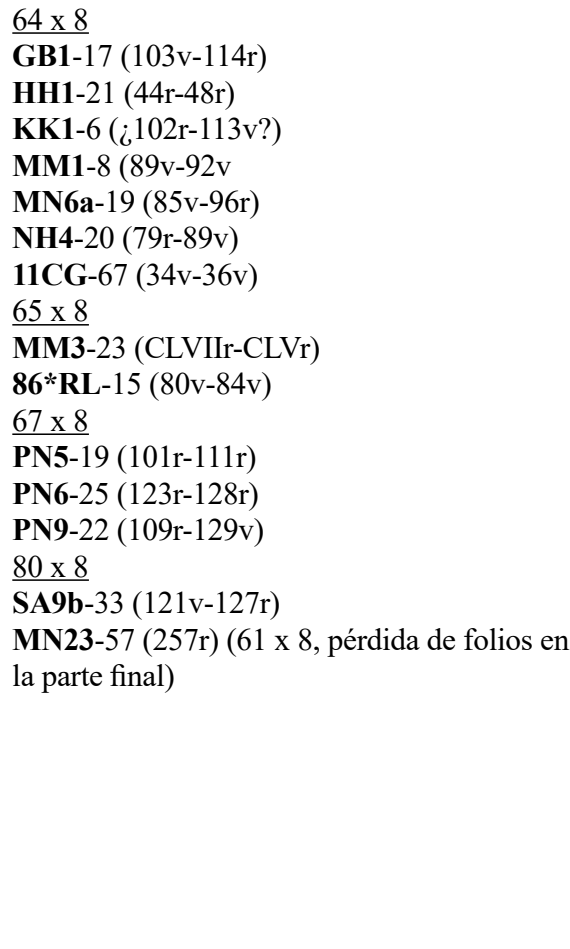 \\
\hline
\end{tabular}


Maria Mercè LóPEZ CASAS

\begin{tabular}{|c|c|c|c|c|}
\hline $\begin{array}{l}17 \\
{[84 \mathrm{v}-85 \mathrm{r}]}\end{array}$ & $\begin{array}{l}\underline{2896} \text { Ervías } \\
(5 \times 10,5)\end{array}$ & $\begin{array}{l}\text { Lumbre mas } \\
\text { clara quel dia } \\
\ldots . . . . \\
\text { salberga el } \\
\text { spiritu santo }\end{array}$ & $\begin{array}{l}\text { Coplas de nuestra } \\
\text { señora } \mid \text { fechas por } \\
\text { erujas } \\
\text { [Tabla-13] Obra de } \\
\text { eruias en loor de } \\
\text { nuestra señora a cartas } \\
\text {.lxxxiiij . }\end{array}$ & $\begin{array}{l}\text { ML1-8 (101r-v) } \\
\text { 92VC-8 (LXXVIIr) } \\
\text { 95VC-8 (77r) }\end{array}$ \\
\hline $\begin{array}{l}\mathbf{1 8} \\
{[85 r-86 r]}\end{array}$ & $\begin{array}{l}\text { 3368 Gómez } \\
\text { Manrique } \\
(15 \times 8)\end{array}$ & $\begin{array}{l}\text { O tu reyna que } \\
\text { beata } \\
\ldots \ldots . . \\
\& \text { de ti }\end{array}$ & $\begin{array}{l}\text { Los siete cuchillos } \\
\text { que firieron | an } \\
\text { nuestra señora } \\
\text { fechos por go } \mid \text { mez } \\
\text { manrrique } \\
\text { [Tabla-14] Los .vij. } \\
\text { cuchillos que firieron } \\
\text { an nuestra señora } \\
\text { fechos por } \mid \text { gomez } \\
\text { manrique a cartas } \\
\text {.lxxxv. }\end{array}$ & $\begin{array}{l}\text { MN24-67 (120v-123r) } \\
\text { MP3-82 (360-364) } \\
\text { SM5a-5 (85r-86r) }\end{array}$ \\
\hline $\begin{array}{l}19 \\
{[86 r-89 r]}\end{array}$ & $\begin{array}{l}\text { Ruiz de Sevilla } \\
(53 \times 8)\end{array}$ & $\begin{array}{l}\text { Mundanos } \\
\text { desseos me no } \\
\text { ocupando } \\
\ldots \ldots . . \\
\text { a quien los } \\
\text { angelicos choros } \\
\text { loaron }\end{array}$ & $\begin{array}{l}\text { Una coronacion de } \\
\text { nuestra señora fecha } \mid \\
\text { por el bachiller fernan } \\
\text { ruyz de seuilla } \\
\text { [Tabla-15] La } \\
\text { coronacion de nuestra } \\
\text { señora fecha } \mid \text { por el } \\
\text { bachiller ferna } n \mid \text { ruyz } \\
\text { de seuilla a cartas } \\
\text {.lxxxvj. }\end{array}$ & $\begin{array}{l}\text { PN6-35 }(167 \mathrm{r}-137 \mathrm{v}) 19 \times 8 \\
\text { (anónimo) (explicit honravan la fiesta estas } \\
\text { criaturas) }\end{array}$ \\
\hline 20 [89v] & $\begin{array}{l}\underline{0511} \text { Gonzalo } \\
\text { Martínez de } \\
\text { Medina } \\
(8 \times 8,4) \\
\text { [rúbrica de } \\
\text { los } 4 \text { versos] } \\
\text { Conclusión }\end{array}$ & $\begin{array}{l}\text { Dime quien eres } \\
\text { tu grande anibal } \\
\ldots \ldots . . \\
\text { sin temor de } \\
\text { llamas \& fuego } \\
\text { quemante }\end{array}$ & $\begin{array}{l}\text { Sigue se vn decir de } \\
\text { gonçalo martines } \\
\text { de medina contra el } \\
\text { mundo } \\
\text { [Tabla-16] Un dezir } \\
\text { de gonçalo martinez } \\
\text { de medina contra } \\
\text { el mundo | a carras } \\
\text {.lxxxviiij . }\end{array}$ & $\begin{array}{l}\text { MH1-248 (370r-v) } \\
\text { (Diego Martínez) }\end{array}$ \\
\hline 21 [90r] & $\begin{array}{l}\frac{6005}{\text { Martínez de }} \\
\text { Medina } \\
(3 \times 8,4) \text { [rú- } \\
\text { brica de los } 4 \\
\text { versos] Finida }\end{array}$ & $\begin{array}{l}\text { Por desconos- } \\
\text { centia se perdio } \\
\text { la luz } \\
\ldots \ldots . . \\
\text { dudosa le viene } \\
\text { la buena ventura }\end{array}$ & $\begin{array}{l}\text { Otro dezir del mesmo } \\
\text { de gonçalo martinez } \\
\text { [Tabla-17] Otro del } \\
\text { mismo de gonçalo a } \\
\text { cartas .xc. }\end{array}$ & UNICUM \\
\hline
\end{tabular}


MATERIALIDAD Y ESTRUCTURA DE UN TEMPRANO CANCIONERO COLECTIVO INCUNABLE ( 86 *RL)

\begin{tabular}{|c|c|c|c|c|}
\hline $\begin{array}{l}22 \\
{[90 \mathrm{r}-\mathrm{v}]}\end{array}$ & $\begin{array}{l}\frac{1664}{\text { Fer- }} \\
\text { nán Sánchez } \\
\text { Calavera } \\
(10 \times 8)\end{array}$ & $\begin{array}{l}\text { Señora muy } \\
\text { linda sabed que } \\
\text { vos amo } \\
\ldots \ldots . . \\
\text { [explicit] todo } \\
\text { junto en vn rato } \\
\text { [explicit sin la } \\
\text { esparsa final] } \\
\text { sus lagrimas } \\
\text { siembra con } \\
\text { mucha tristura }\end{array}$ & $\begin{array}{l}\text { Un dezir de fernand } \\
\text { sanchez talauera | } \\
\text { a vna donzella \& } \\
\text { respuesta della } \\
\\
\text { [Tabla-18] Un otro } \\
\text { dezir de fernan } \\
\text { sanchez talauera a } \\
\text { vna dama fecho | por } \\
\text { dyalogo : \& concluye } \\
\text { en virtud a cartas . xc. }\end{array}$ & PN1-538 (181r-v) 10 x 8 \\
\hline $23[90 v]$ & $\begin{array}{l}\text { 3626 Según } \\
\text { Dutton desfe- } \\
\text { cha de } 1664 \\
(1 \times 9) \\
\text { (Dutton con- } \\
\text { sidera que en } \\
86 * \text { RL es anó- } \\
\text { nima. Pero está } \\
\text { vinculada por } \\
\text { el tema al decir } \\
\text { de Talavera, y } \\
\text { por la rúbrica } \\
\text { fin de la obra. } \\
\text { El hecho de que } \\
\text { no figure en la } \\
\text { tabla también } \\
\text { induce a pensar } \\
\text { que para Llavia } \\
\text { formaba parte } \\
\text { de la obra de } \\
\text { Talavera }\end{array}$ & $\begin{array}{l}\text { Haue con los } \\
\text { hombres paz } \\
\text {...... } \\
\text { todo junto en vn } \\
\text { rato }\end{array}$ & $\begin{array}{l}\text { [Tabla-18] Un otro } \\
\text { dezir de fernan } \\
\text { sanchez talauera a } \\
\text { vna dama fecho | por } \\
\text { dyalogo : \& concluye } \\
\text { en virtud a cartas . xc. } \\
\text { Esparça \& fin de la } \\
\text { obra }\end{array}$ & $\begin{array}{l}\text { BM1-13 (21v) Pere Torrelles (Maldecir de } \\
\text { mujeres) }\end{array}$ \\
\hline $\begin{array}{l}\mathbf{2 4} \\
{[91 \mathrm{r}-98 \mathrm{r}]}\end{array}$ & $\begin{array}{l}\underline{6006} \text { Fray } \\
\text { Gauberte } \\
(197 \times 6)\end{array}$ & $\begin{array}{l}\text { Mas dezid me } \\
\text { fray gauberte } \\
\ldots \ldots . . \\
\text { de virtudes \& de } \\
\text { vidas | } \\
\text { de razon }\end{array}$ & $\begin{array}{l}\text { Razonamjento de } \\
\text { fray Gau// | berte } \\
\text { del monge con el } \\
\text { cauallero | sobre la } \\
\text { vida venidera } \\
\text { [Tabla-19] } \\
\text { Razonamiento de fray } \\
\text { gauberte del monge } \\
\text { con con el cauallero | } \\
\text { sobre la vida venidera } \\
\text { a cartas .xcj. }\end{array}$ & UNICUM \\
\hline
\end{tabular}

Recibido: $13 / 03 / 2020$

Aceptado: 30/04/2020 
$\cos 8$

\author{
MATERIALIDAD Y ESTRUCTURA DE UN TEMPRANO \\ CANCIONERO COLECTIVO INCUNABLE $(86 *$ RL)
}

Resumen: Estudio del Cancionero de Ramón de Llavia (86*RL), estampado en Zaragoza, en el taller de Pablo Hurus. Se trata de un impreso singular, no solo por ser uno de los primeros cancioneros colectivos incunables, sino también por los poemas representados en él, que van desde los más difundidos (en manuscrito e impreso), como los de Fernán Pérez de Guzmán, Juan de Mena, Íñigo de Mendoza o los Manrique, hasta los que solo se han conservado en dos o tres testimonios, e incluso hay dos unica. Se presenta el análisis material del incunable (con referencia a los seis ejemplares conservados); así como la estructura y selección de los textos que lo conforman. De cada poema se incluye su tradición textual.

Palabras Clave: Cancionero de Ramón de Llavia. Incunable. Poesía de Cancionero. Fernán Pérez de Guzmán. Bibliografía material.

\title{
Materiality and Structure of an Early Collective INCUNABULUM CANCIONERO (86*RL)
}

\begin{abstract}
Study of Cancionero de Ramón de Llavia (86*RL), printed in Zaragoza at Pablo Hurus printing house. This is a singular printing, not only as one of the first collective incunabula cancioneros, but also for the poems which are in it contained, which go from the most widespread ones (in manuscript and printing), like Fernán Pérez de Guzman's, Juan de Mena's, Iñigo de Mendoza's or Manrique's, to those which have only been preserved in two or three testimonies, and there are even two unica. We present the material analyses of the incunabulum (with reference to the six preserved exemplars) and the structure and selection of its texts. We include the textual translation of each poem.
\end{abstract}

Keywords: Cancionero de Ramón de Llavia. Incunabulum. Cancionero poetry. Fernán Pérez de Guzmán. Material bibliography. 